\title{
O FERRO EM BIOLOGIA
}

Processos colorimétricos para a dosagem desse elemento Aplicação do método de Salomé Pereira á determinação do ferro sérico

POR

\section{Rubens Salomé Pereira}

e

J. Onofre Araujo

Livre docentes da Universidade de S. Paulo

I

Elemento essencial ao organismo, de larga significação biológica, o ferro desempenha papel de singular relevo, o que de pronto se demonstra pelo fato de ele fazer parte da molécula da hemoglobina. Schmidt (1) acha que dieta isenta desse metal causa, se não imediatamente, um pouco mais tarde, ou na segunda geração, o aparecimento do estado anêmico. $\mathrm{O}$ estudo das funções exercidas por esse corpo é, pois, de interesse inegavel e alto.

- Numa série brilhantíssima de investigações que lhe valeram o prêmio Nobel de 1931, Hans Fischer estabeleceu a estrutura de um grupo de corantes pirrólicos cujo núcleo fundamental é a porfina, complexo de quatro núcleos de pirrol reunidos por quatro grupos metina $=\mathrm{CH}-$ designados pelas letras $\alpha, \beta, \gamma, \delta$.

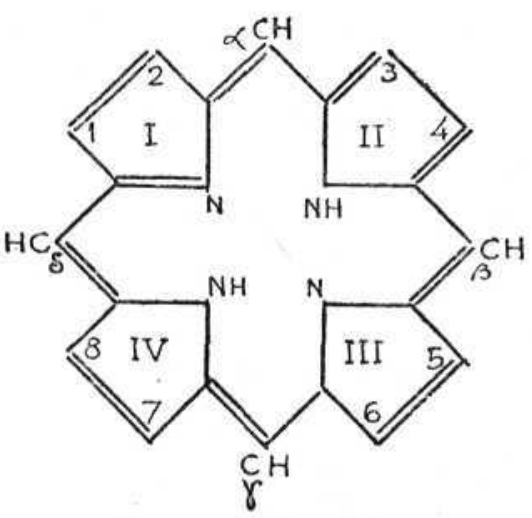

As porfirinas dela se derivam pela substituição dos átomos de hidrogênio, dos $C$ numerados de 1 a 8, por grupos metila, etila, vinila, restos de ácido, etc. A introdução do $\mathrm{Fe}^{++}$na molécula porfiri-

** Comunicado à Sociedade de Biologia de S. Paulo, em 8-II-1941. 
nica produz corpos cristalisaveis - os hemes - estaveis em presença do ácido acético, decomponiveis pelo ácidos fortes, transformaveis, por oxidação, em sais de hemina. Ao passo que os hemes facilmente se oxidam, as heminas são estaveis.

ANSON e Mirsky (2) verificaram, em tecidos variadíssimos, animais e vegetais, a presença de complexos ferro-porfirínicos, por eles denominados "heme» e considerados de distribuição universal. A hemoglobina é forma particular de heme.

O tratamento do sangue pelo ácido acético, em presença do cloreto de sódio, a quente, fornece, ao resfriar-se o sistema, cristais negro-violacios, de hemina - cristais de Teichmann - (3).

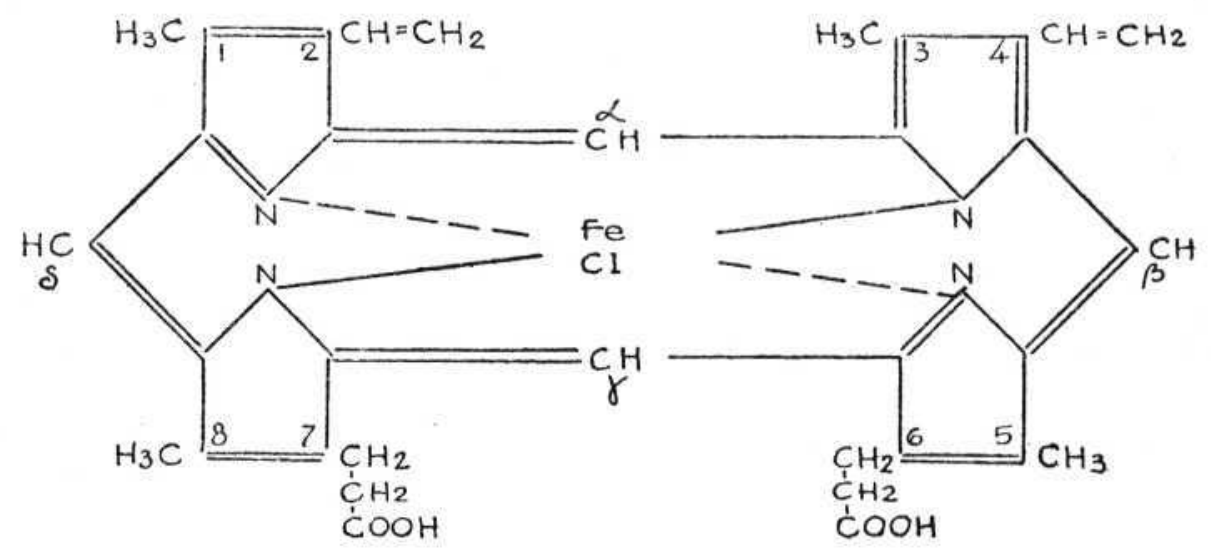

A substituição do $\mathrm{Cl}$ pelo $\mathrm{OH}$, que os alcalis realizam facilmente, transforma a clorhemina em oxihemina. Tratando-se uma solução potássica de clorhemina, pelo ácido acético; lavando-se e secandose o precipitado obtido; dissolvendo-se este pela piridina; filtrando-se a solução e ajuntando-se à mesma eter de petróleo, conseguir-se-ão belos cristais de oxihemina, a verdadeira hematina (Hans Fischer).

A capacidade, que o sangue possue, de transportar o oxigênio, deve-se à hematina graças, provavelmente, à adição do $O$ ao $\mathrm{Fe}$ do complexo. Levar esse gás aos tecidos e às celulas em que baixa é a tensão desse elemento, é função da hemoglobina, que nenhuma ação catalítica exerce nos fenómenos respiratórios.

Se compararmos a fórmula de clorofila a (Hans Fischer) com a da hematina, notaremos a existência de semelhança notavel, que revela serem, os mais imporantes pigmentos do reino animal e do vegetal, modificações da mesma estrutura. Para GoRTNer (4) essa estreita relação se deve aos processos da evolução orgânica; o núcleo fundamental do pigmento anterior modifica-se para poder preen- 
cher as funções especiais requeridas pelo reino animal: o magnesio cede logar ao ferro, que vem exercer as funções de transportador de oxigênio; o fitol é substituido por um residuo proteico originado, possivelmente, dos amino-ácidos fornecidos pelos alimentos, visto os animais não serem capazes de efetuar a síntese do referido alcool.

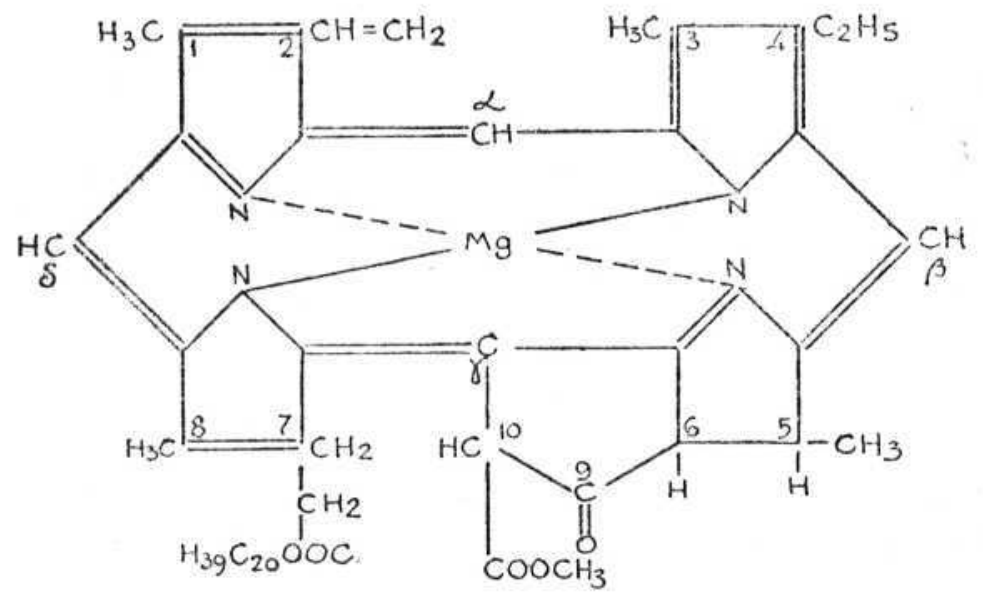

Nessa ordem de idéias, é digna de menção a espirografishemina, de Warburg e Negelein. Em certos vermes (Spirographis) cujo sangue é corado de verde por um pigmento ferrifero - a clorocruorina - esses pesquizadores encontraram uma hemina que apresenta um

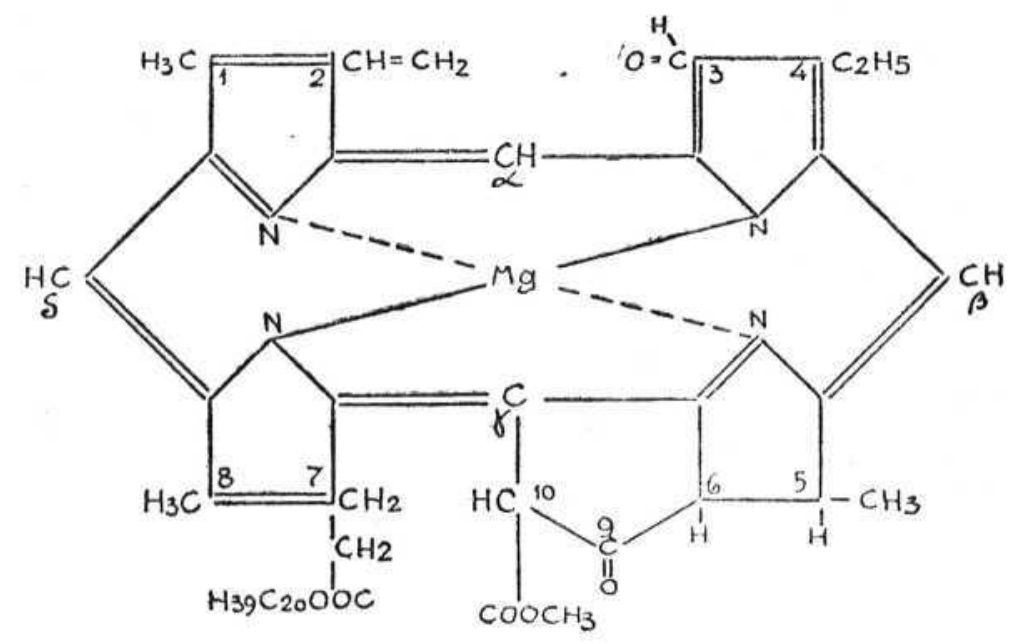

grupo $C=O$ alem de dois carboxilos. Esse corpo é visinho da clorofila $b$ que difere da $a$ por apresentar, na posição 3, um grupo formila em logar de metila. 
- Digno de nota é o efeito catalítico do ferro na síntese da clorofila, tão bem demonstrado pelas belíssimas experiências de ODDo e PollacCi (5) (6). A essa ação do ferro em relação ao pigmento verde dos vegetais, deve-se acrescentar a do cobre, na formação da hemoglobina. Ao considerarmos a existencia de pigmentos cupríferos - as hemocianinas - em moluscos, em crustáceos, em arachnídeos; a presença do manganês na pinaglobulina (Pinna squamosa); a do vanádio no sangue de certos ascidios, notaremos de pronto que há relações estreitíssimas entre os pigmentos porfirínicos encontrados nos animais e nos vegetais.

Em várias espécies, a influência do cobre na formação da hemoglobina já se acha bem estabelecida (7). Schultze e colaboradores (8) verificaram que ratos anêmicos se apresentam notavelmente desprovidos desse metal, e que a adição de ferro e de cobre à dieta durante um período de sete dias determina baixa retenção do último - cerca de $5 \%$ apenas - se bem que se dê máxima formação de hemoglobina. Os mesmos pesquizadores mostraram que, nos porcos, a anemia pode originar-se apenas da deficiência de ferro, e que, no caso de haver reserva corporal de cobre, o estado anêmico se melhora pela simples adição de ferro aos alimentos. Se houver, ao mesmo tempo, «deficit» de cobre, porem, alimentação rica dè ferro somente, não corrige a anormalidade.

Os trabalhos de Underwood e Elvehjem (9) mostraram que o ferro, o cobre e o manganês são os únicos elementos minerais que se devem ajuntar à dieta láctea para que os ratos se desenvolvam normalmente, e que o cobalto, corpo que geralmente contamina os sais de ferro, não exerce influência perceptivel no tratamento da anemia láctea desses animais. De acordo com esses investigadores, as exigências diarias do rato, em quanto ao cobalto, devem ser inferiores a 0.6 de micrograma.

- A hemosiderina, que se encontra em certas células do fígado, do baço e dos rins, e que parece ser hidrato de ferro coloidal, provem, sem dúvida, da destruição da hemoglobina e constitue importante fonte endógena de ferro. Соок (10), que a isolou dos tecidos, mostrou que ela encerra pequena quantidade de um pigmento amarelo-escuro e um composto do ferro que, analisado, revelou ser formado de $55 \%$ de $\mathrm{Fe}$, de $12,5 \%$ de $\mathrm{H}$, de $27 \%$ de $\mathrm{O}$ e de traços - impurezas, provavelmente - de carbono e de azoto.

A presença de proteinatos de ferro tem sido assinalada por vários investigadores. Assim, HaMmARSTEN e BUNGe isolaram corpos dessa natureza, do pancreas do boi e da gema do ovo. O ferro 
no embrião da cevada, acha-se sob forma de nucleina. Petit, que isolou essa nucleina, diz que nela há $1,1 \%$ de $P$ e $0.195 \%$ de $F e$. Do Rumex obtusifolius, por meio do alcool clorídrico, TARBOURIECH e SAGET extrairam um composto orgânico ferruginoso em que há $6.36 \%$ de ferro. A existência de fosfo-proteinatos de ferro pode ser explicada pela combinação dos grupos fosfóricos com o ferro ionisavel que, nesses compostos, não se encontra dissimulado.

- O estudo da significação do ferro na célula viva foi empreendido em WARBURG (11) para quem esse elemento desempenha no protoplasma, o papel de catalisador, graças à capacidade de facil oxidação. Em trabalhos posteriores (12), WARBURG mostrou que essa atividade se deve a um composto tetrapirrólico do ferro, em que ele vê o fermento respiratório. WARBURG (13) observa que a hematina se acha presente em células e em tecidos animais e vegetais, de sorte que pode ser tida por corpo de distribuição universal, A diferença a assinalar é que nas hemácias ela se encontra combinada à globina, aq passo que nas outras células ela pode estar livre, ou ligada a corpos diversos.

E' sabido que o $C O$ exerce ação tóxica devido à formação do composto «hemoglobina-monóxido de carbono», em que aquele se prende mais fortemente ao ferro do que o faz o oxigênio. As experiências de HaLDANE, em que a morte de ratos se determinou pela exposição deles a uma atmosfera de monóxido de carbono, são interpretadas por WARBURG no sentido do deslocamento do oxigênio da molécula da hemoglobina: os animais perecem por falta de oxigênio. No caso de os ratos se transferirem, antes de a morte sobrevir, para ambiente ricamente oxigenado, sobrevivem, apesar de a hemoglobina permanecer ligada ao $\mathrm{CO}$, graças ao grande aumento de oxigênio dissolvido no plasma, que acorre às necessidades dos processos respiratórios dos tecidos. WARBURG observa que essas experiências mostram que o $C O$ não afeta a respiração celular, mesmo que toda a hemoglobina se sature desse gás. Daí deriva ele a teoria de que a enzima responsavel pelo mecanismo da respiração é a hematina, ou um derivado dela. Warburg nota, ainda, que o fermento respiratório apresenta as três características da hemoglobina:

1) reversibilidade da reação com o oxigênio e com o monóxido de carbono

2) identidade do coeficiente de distribuição $-\frac{\mathrm{HbO}_{2}}{\mathrm{HbCO}}-\frac{\mathrm{CO}}{\mathrm{O}_{2}}=\mathrm{K}$ desses dois corpos

3) sensibilidade da combinação com o monóxido de carbono, à luz. 
A diferença entre a hemoglobina e o fermento respiratório reside no fato de este agir como catalisador e na impossibilidade em que aquela se acha, de o fazer. Para WARBURG, as propriedades desse fermento mais o aproximam da hematina livre do que da hemoglobina. Sabe-se que a hematina oxida cataliticamente a cisteina, em meio aquoso, dando cistina, e que o fenómeno é inhibido pelo monóxido de carbono. A combinação da hematina com a piridina, ou com a nicotina, produz catalisadores extremamente poderosos, capazes de transportar 2.000 moléculas de oxigênio por molécula de hemonicotina, ou de hemopiridina, para a cisteina.

WARBURG sugere - e isso resulta das suas pesquisas relativas à influência da luz de diferentes comprimentos de onda sobre a respiração celular - que o fermento respiratório seja a hematina combinada com base ainda não definida. Na célula ele não se acha em solução, e sim adsorvido à superfície dos componentes sólidos da mesma.

Esses brilhantíssimos estudos de WARBURG confirmaram-se por outros investigadores, e hoje admite-se geralmente que o fermento respiratório de todas as células seja um derivado da hematina.

Stern (14) mostrou que a catalase - enzima isolada e cristalizada por Sumner e Dounce (15) - é um fermento hematinico de que a porfirina é idêntica à do pigmento sanguineo. KEILIN e MANN admitem que o grupo protético da peroxidase da rabiça seja um composto hemínico.

Os corpos específicos das reações dos ferro-proteidos nos seres vivos são o oxigênio molecular que oxida o $\mathrm{Fe}^{++}$, e o ferro citocromo que reduz o $\mathrm{Fe}^{+++}$. A forma oxidada dos ferro-proteidos $-\mathrm{Fe}^{+++}-$ oxida o ferro-citocromo, e transforma-o em ferri-citocromo. Para SzentGIoRgy, o corpo específico da reação do ferri-citocromo é o ácido sucínico, ao passso que para THEORell é a dihidroaloxazina (17). Em trabalhos recentíssimos, porem, HaAs, Horecker e Hogness (18) isolaram uma nova flavoproteina - a redutase do citocromo $c$ - de altíssima atividade, cujo peso molecular foi calculado em 75000 , e que completa a cadêia de oxido-reduções entre o hexose-monofosfato e o citocromo $c$. Essa nova enzima, cujo grupo prostético é o mononucleótido aloxazínico, coloca-se em posição de importante fator biológico, e o fato de haver, até então, escapado à observação dos pesquisadores se deve à sua grande instabilidade, quando comparada à de outras flavoproteinas, pois submetida ao tratamento que habitualmente a estas se dá para fins de isolamento, perde toda a sua atividade.

No preparo do fermento amarelo, Warburg e Christian manteem os seus produtos durante 24 horas em acetona a $33 \%$ : nessas condições a enzima de HAAs e colaboradores inativa-se completamente no 
espaço de uma hora. Para fins de purificação, Warburg e Christian agitam as suas preparações, conservadas à temperatura de $38^{\circ}$, durante 24 horas: a capacidade redutora do novo fermento de HaAs et allii, em relação ao citocromo $c$, abaixa-se $63 \%$ da inicial quando se põe a $40^{\circ}$ durante 10 minutos.

A redutase do citocromo $c$ reage com a forma oxidada deste, de acordo com a equação.

Forma reduzida da redutase do citocromo $\mathrm{c}+2 \mathrm{Cy} \mathrm{Fe}^{+++}=$ $=$ Redutase do citocromo $c+2 \mathrm{Cy} \mathrm{Fe}++2 \mathrm{H}$

HaAs e colaboradores mostraram que o novo fermento reage especificamente com o citocromo $c$, ao passo que o amarelo, de WARBURg e Christian não o faz.

Essa descoberta tem alto valor biológico, pois, apesar de várias flavoproteinas conhecidas reagirem com o nucleotido trifosfopiridínico, nenhuma age diretamente sobre o citocromo $c$. As reaçồes entre a forma reduzida do fermento amarelo, de Warburg e Christian, e o oxigênio são muito lentas, e não apresentam grande importância fisiológica. THEORELl (19) observou a redução do citocromo $c$ por este fermento amarelo, mas a lentidão do processo exclue significação biológica de monta.

Altschul, Abrams e Hogness (20), estudando o mecanismo da oxidação do citocromo $c$ reduzido, verificaram que este rapidamente se oxida por pequeníssimas quantidades de $\mathrm{H}_{2} \mathrm{O}_{2}$, por intermédio duma peroxidase extremamente ativa, e isolaram e purificaram uma nova enzima - a peroxidase do citocromo $c$ - que reage especificamente com o citocromo $c$ reduzido. Até então, não havia demonstração perentória de as peroxidases reagirem com algum dos componentes do sistema respiratório.

A reação entre a forma reduzida do citocromo $\mathrm{c}$ e o $\mathrm{H}_{2} \mathrm{O}_{2}$ assim se representa

$$
2 \mathrm{Cy} \mathrm{Fe}^{++}+\mathrm{H}_{2} \mathrm{O}_{2}+2 \mathrm{H}=2 \mathrm{Cy} \mathrm{Fe}^{+++}+2 \mathrm{H}_{2} \mathrm{O}
$$

A velocidade dessa oxidação é diretamente proporcional à concentração do citocromo $c$ e à da peroxidase. Esta é um fermento hematínico e a sua atividade é comparavel à das mais ativas preparações de catalase.

- O grupo prostético do citocromo $c$ é um residuo ferro-porfirínico idêntico, parece, à ferro-porfirina hemoglobínica. O citocromo forma um sistema oxido-redutor reversivel.

O fermento amarelo, de Warburg e Christian (21) preside, ao que parece, à respiração celular na ausencia do ferro: nele o grupo prostético é um ester-riboflavino-fosfórico. 
- O ferro é, como se vê, elemento essencial à vida, e as suas funções específicas não podem ser exercidas por nenhum outro elemento: sob o ponto de vista biológico, pois, o conhecimento exato do papel que esse corpo desempenha nos fenómenos vitais, é de alta e singular significação.

\section{PROCESSOS COLORIMETRICOS PARA A DOSAGEM DO FERRO}

A importância do conhecimento da quantidade de ferro presente nos meios biológicos é muito grande, e claramente se evidencia pela atenção dada a esse problema por numerosos pesquisadores, e pelo grande número de trabalhos relativos a esse assunto, aparecidos na literatura durante os últimos anos.

A escolha do processo para a dosagem dos corpos é matéria de ordem interna dos laboratórios. Os métodos, porem, devem obedecer aos requisitos usuais de segurança, de rapidez, de adaptação ao material que se estuda e, tanto quanto possivel, de economia. E' de toda a conveniência que eles sejam, alem disso, simples, comodos, de facil execução.

No estudo de muitos tipos de material biológico tem-se tornado de extrema importância a determinação exacta de quantidades pequeníssimas de ferro. Graças à grande sensibilidade que, por via de regra, apresentam as reações coloridas, estas particularmente se indicam para os trabalhos nos domínios da microquímica, e numerosos são os métodos colorimétricos que se encontram na literatura relativa à dosagem do ferro.

Parece-nos de toda a conveniência, nesta altura, examinar, de leve ao menos, os métodos que mais em evidência se teem posto.

\section{MÉTODO DO TIOCIANATO}

A reação colorida que se produz quando o ionio $\mathrm{Fe}+++$ se coloca, sob certas condições, em presença do ionio $\mathrm{CNS}^{-}$, é conhecida desde 1837 e se deve a H. Ossian. Schlesinger e Van Velkenburah (22) mostraram, pelo estudo dos espetros de absorpção tanto das soluções aquosas como das etéreas, e pela eletrólise dos solutos aquosos, que a cor vermelha se deve ao ionio complexo

$$
\left[\mathrm{Fe} \quad(\mathrm{C} \mathrm{NS})_{6}\right]^{\cdots-\cdot}
$$

Vários pesquisadores demonstraram que os iodatos, os cloretos alcalinoterrosos, os nitritos, os nitratos, os fluoretos, os fosfatos, os arseniatos, os sulfatos, etc., impedem, retardam, perturbam o desenvolvimento da cor. A influência do $\mathrm{SO}_{4}$ deve-se à formação dum ionio complexo de fórmula provavel

$$
\left[\mathrm{Fe} \quad\left(\mathrm{SO}_{4}\right)_{2}\right]^{-}
$$

menos estavel do que o complexo ferri-tiocianato, de sorte que a adição de grande excesso de tiocianato alcalino favorece, de acordo com a lei da ação das massas, largamente a produção do complexo colorido.

Os oxalatos, os corpos orgânicos hidroxilados - tartaratos, citratos, etc. - os compostos, enfim, capazes de dar com o $\mathrm{Fe}+\mathrm{H+}$ complexos estaveis, podem, se deles houver quantidades suficientes, unir-se ao metal de tal sorte que deste não restem ionios livres para se combinarem com o tiocianato. E', pois, possivel 
obter-se reação negativa do $\mathrm{Fe} e^{+++} \mathrm{com}$ o $\mathrm{CNS}^{-}$mesmo na presença desse cationio. $\mathrm{O}$ mercurio produz os mesmos efeitos, graças à formação do complexo

pouco dissociavel.

$$
\left[\mathrm{Hg}(\mathrm{CNS})_{4}\right]^{--}
$$

A influência dos nitritos deve-se ao tiocianato de nitrosila

\section{NO. CNS}

que se forma em solução ácida e cuja cor muito se assemelha à do complexo ferri-tiocianato. Se bem que a coloração devida ao tiocianato de nitrosila se destrua pelo aquecimento, o calor não é menos aconselhavel para se eliminar a influência desse corpo, pois a temperatura elevada tambem age desfavoravelmente no caso do $\left[\mathrm{Fe}(\mathrm{C} \mathrm{NS})_{6}\right]^{-\cdots}$

A transformação completa do $\mathrm{Fe}+++$ em $\left[\mathrm{Fe}\left(\mathrm{SNS}_{6}\right]^{\cdots}\right.$ não dissociado, requer o emprego de quantidades relativamente grandes, de tiocianato alcalino. Ora, este reativo exerce ação redutora, e disso resulta a necessidade de se usarem porções largas, de oxidantes, afim de o ferro manter-se na forma trivalente, o que determina, por seu turno, certa destruição da cor produzida. Essas sérias dificuldades tornam necessária a extração, do meio em que se formou, do

$$
\left[\mathrm{Fe}(\mathrm{CNS})_{6}\right]^{--\cdot}
$$

por meio de solventes orgânicos, e, para tanto, vários teem sido aconselhados: o eter sulfúrico, o acetato de etila, a mistura de eter sulfúrico com alcool metílico, a constituida pelo mesmo eter e pelo alcool amílico, o alcool isoamílico, etc.

A cor produzida pelo complexo ferri-tiocianato desmáia mais ou menos rapidamente, e isso, até certo ponto, depende da técnica empregada. THOMPSON e colaboradores (23) aconselham medir de antemão as quantidades necessárias, de tiocianato alcalino e coloca-las em tubos de experiência graduados, ou em volumétricos de capacidade conveniente, de modo a reduzir-se o mais possivel o tempo de contato, nos trabalhos em série, entre os corpos $-\mathrm{Fe}+++\mathrm{e}(\mathrm{CNS})^{-}$ - antes de se efetuarem as medidas colorimétricas.

ROBERTS e colaboradores (24) acham, ao estudar o desenvolvimento da cor em presença do ácido clorídrico, e em meio acidificado pelo ácido sulfúrico, que a intensidade da coloração varia em razão inversa à concentração dos ácidos, e que, em igualdade de condições, durante a extração do complexo colorido pelo alcool isoamílico, o $\mathrm{SO}_{4} \mathrm{H}_{2}$ produz cor mais intensa do que a obtida pelo emprego do $\mathrm{Cl} \mathrm{H}$.

Se bem que a reação do tiocianato seja muito sensivel, e continue a ser muito empregada para a determinação microquímica do $\mathrm{Fe}+++$, ainda que ela seja a base sobre que repousa grande parte dos nossos conhecimentos referentes às concentrações do ferro nos meios biológicos; apesar das numerosas modificações por que esse método tem passado, e dos resultados felizes de algumas delas, as dificuldades encontradas fazem que os pesquisadores recebam com satisfação a proposta de novos processos.

\section{MÉTODO DE BERNOULLI (25)}

Os sais de $\mathrm{Fe}+++$ dão, em presença do pirocatecol, cor verde que, pela adição de soda, ou de amoníaco, se muda em vermelho, reação muito característica dos compostos ortodioxibenzoicos, graças à formação dum sal complexo. 
Essa reação, que permite verificar-se a presença de duas microgramas de $\mathrm{Fe}+++$ em $0.1 \mathrm{cc}$ de solução, foi proposta por Bernoulli para fins quantitativos.

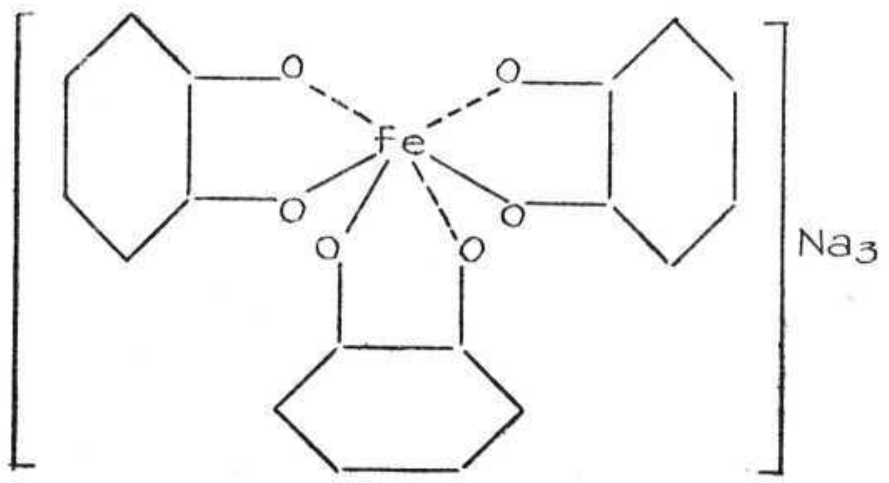

De acordo com a literatura de que dispomos, esse processo não tem sido muito estudado, e o trabalho não teve até hoje, ao que parece, a aceitação que provavelmente merece.

\section{METODO DE VAN URK}

Em 1926, Van URK propoz para agente cromogênico, na determinação quantitativa do ferro, o piramido, fornecido pela metilação da 4-aminoantipirina. Em presença do $\mathrm{Cl}_{3} \mathrm{Fe}$, a antipirina dá cor vermelha, muito intensa, ao passo que o piramido produz em meio ácido $(\mathrm{Cl} \mathrm{H})$, com o $\mathrm{Fe}+\mathrm{H}$, coloração violeta que rapidamente se torna ocreosa.

$\mathrm{Na}$ literatura que temos à mão, raras referências se acham a esse método.

\section{METTODO DE LYONS}

Em 1879, ANDREASCH (28) mostrou que o ácido tioglicólico dá, em presença do ferro, cor vermelha, mas, em que pese à importância da descoberta, só em 1927 Lyons propoz o emprego desse reagente para fins quantitativos, atribuindo o desenvolvimento da cơr à formação dum complexo do $F e^{++}$e acreditando que o $\mathrm{Fe} e^{+++}$se reduzisse a $\mathrm{Fe}^{++}$. O assunto foi estudado por CanNan e Richardson (29), os quais verificaram que, na ausência total de oxigênio, o ionio $\mathrm{Fe} e^{+++}$, ajuntado a uma solução de tioácido tamponada de sorte que o pH se mantivesse entre 6 e 11, produz de pronto cor intensamente vermelha que logo começa a desmaiar com velocidade proporcional ao aumento dos ionios $H$ livres. A' altura de $p H=7$, a mudança é instantânea. A solução corada sobre ser sujeita a esmaecimento espontâneo, pode destingir-se prontamente sob a ação de redutores, como o hidrosulfito de sodio, p. ex. Nesse caso, a cor facilmente se restabelece pela adição de oxidantes, como o azul de metileno. Quando, após numerosas oxidações e reduções, o ferro começa a precipitar-se, observa-se a transformação de quase todo o $R$-SH em $R-S S-R$.

A capacidade, que o $\mathrm{Fe}^{+++}$possue, de produzir cor vermelha, diminue rapidamente, à medida que a acidez se enfraquece, e quando o $\mathrm{pH}$ se situa acima de 10 , ha tendência manifesta de precipitar-se o metal. Se o $\mathrm{Fe}+++$ se adiciona a uma solução de $R-S H$ de acidez mais forte do que a representada pelo $p H=4$, aparece tonalidade azul passageira, que se substitue à vermelha 
produzida em soluto cujo índice de acidez seja 6. A variação, dentro desses limites, da quantidade de ionios $H$ livres, faz que uma cor se misture com a outra e a mudança da tonalidade parece definir-se melhor à altura do $p H=5$. Os solutos incolores que se sucedem aos azulados em meio de $p H$ inferior a 4 não se coram pelos oxidantes e, alcalinisados, nenhuma cor dão na ausência do oxigênio: os agentes de oxidação, porem, determinam prontamente o desenvolvimento do vermelho.

Os sais ferrosos não produzem cor alguma em presença de $R$-SH, quer a solução deste seja ácida, quer alcalina. A mistura comporta-se, em presença de oxidantes, exatamente como os solutos resultantes da mistura $\mathrm{Fe}+++\mathrm{R}$-SH.

Alem do $\mathrm{pH}$, os fatores mais importantes para a estabilidade da cor vermelha, são a concentração do $F e+++$ e a do $R-S H$. Devido, porem, ao esmaecimento espontâneo da cor, não foi possivel obter-se medida precisa de relações estequiométricas que porventura presidam à influência dessas funções.

A adição de $\mathrm{CN}^{*}$ ao sistema $\mathrm{Fe}+{ }^{++} \mathrm{R}$-SH destroe o vermelho, que não mais se reproduz pela ação dos oxidantes.

CANNAN e Richardson concluem que ambos os ionios $-\mathrm{Fe}^{++}$e $\mathrm{Fe} e^{+++}-$ formam complexos com o R-SH e pensam que o complexo férrico se dissocia mais rapidamente do que o ferroso, a composição de ambos determinando-se pelo índice de coordenação habitual, do ferro. O sistema ferritiol-ferrotiol é reversivel e equilibra-se com outros sistemas reversiveis, de oxido-redução Alem disso, o ferritiol se reduz à custa do $R-S H$, ao passo que o ferrotiol rapidamente se oxida em meio neutro, ou alcalino.

Segundo Sifank e Mellon (30) a cor é estavel durante seis horas, pelo menos à luz difusa do dia, e obedece à lei de Lambert-Beer. Outros investigadores acham que o período de estabilidade da cor não vai alem de meia hora, mas que ela pode volver à primitiva intensidade pela agitação, em contato com o ar.

Uma das grandes vantagens do método de Lyons é a notavel indiferença à ação dos anionios, pois mesmo em concentrações relativamente altas $(0,5 \%)$, os fluoretos, os iodetos, os nitratos, os ortofosfatos, os sulfatos, os cloratos, os tartaratos, os citratos, os oxalatos, os acetatos, os bromatos, os tiocianatos, os sulfitos, os cloretos não teem influência alguma. Os pirofosfatos, os cianetos, os molibdatos, os tungstatos, os nitritos exercem ação prejudicial. Dentre os cationios, o cálcio, o bário, o estrôncio, o alumínio, o cromo dão origem a precipitações em meio amoniacal. O cobalto, o nickel, o cobre, o estanho, o zinco, o cádmio, o chumbo, o manganez, o bismuto, o urânio interferem desfavoravelmente. Na solução em que se vai desenvolver a cor, não se devem encontrar altas percentagens de sódio, ou de amônio, ou de potássio, pois esses corpos favorecem o esmaecimento da cor e induzem a erros.

Apesar de apresentar certas vantagens, o método do ácido tioglicólico não tem dado inteira satisfação aos pesquisadores.

\section{MÉTODO DA DIMETILGLIOXIMA (31)}

Os sais de $\mathrm{Fe}^{++}$, em solução amoniacal e em presença da dimetilglioxima, dão un complexo vermelho, soluvel (32) 


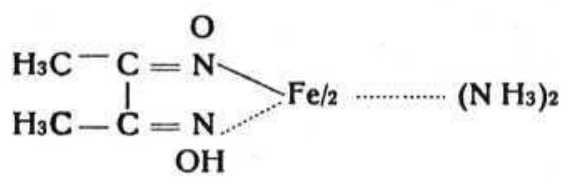

O nikel, o alumínio, o zinco, o magnésio, o cobre, o cobalto interferem e devem eliminar-se da solução (33) (34). Na amostra deve haver 10 a $60 \mathrm{mg}$. de $\mathrm{Fe}$ por litro. O complexo ferroso se oxida ao ar, e o método apresenta certa feição que o torna, por vezes, de aplicação delicada.

\section{MÉTODO DE ZIZ.INE (35)}

DenioÈs propoz a reação aloxânica - coloração azul dos sais de $\mathrm{Fe}{ }^{++}$ em presença do reativo aloxânico do mesmo autor e em meio alcalinisado pelo hidróxido de sódio - para a identificação dos sais ferrosos " Essa cor, porem, se destroe por oxidação. Pelo mesmo autor, a reação da aloxantina é recomendada para o reconhecimento do $\mathrm{Fe}^{+++}$pois mesmo em presença dos ácidoalcooes a cor azul se desenvolve. ZızıNE aplicou esta reação à dosagem do $\mathrm{Fe}$ no sangue.

\section{MÉTODO DO COMPLEXO $\mathrm{Cl}_{5} \mathrm{Fe} \mathrm{H}_{2}$ (36) (37) (38)}

Esse método se funda no desenvolvimento de cor amarela muito intensa devida à formação do ácido cloroférrico $-\mathrm{Cl}_{5} \mathrm{Fe} \mathrm{H}_{2}$ (Denigès) - quando o $\mathrm{Fe}+\mathrm{H}$ se põe em solução clorídrica muito concentrada $(28 \%)$. A cor amarela, a grande acidez exigida pelo processo, entre outras causas, tornam o método pouco atraente.

\section{MÉTODO DE GREGORY (39)}

Em meio acético e em presença do $\mathrm{Fe}{ }^{+++}$, o ácido salicílico produz cor de ametista. Esta reação, publicada por Vogel (40) e estudada por PAoliani (41), foi aproveitada por GREGoRY para fins quantitativos, em 1907. YoE (42) e SNell (43) mostraram que o ácido clorídrico, o nítrico, o sulfúrico, os fosfatos, os tiosulfatos, os bisulfitos, os fluoretos prejudicam a reação. SAGaidachnuu e RAvich dizem que os citratos, os tartaratos, os oxalatos, exercem ação perturbadora, e que a solução a examinar-se não deve apresentar $p H$ inferior a 2. YoE acha que a cor esmaece à luz; SNelL, que ela é estavel durante 48 horas à luz difusa, mas que desaparece rapidamente à do sol. Para MeHLı (44) a cor, dentro dos limites de $2 \%$ de erro, é estavel durante 66 horas nas condições habituais do laboratório.

Numerosos ionios comumente encontrados causam o enfraquecimento da cor, seja devido à formação de complexos incolores com o $\mathrm{Fe}^{+++}$, seja em virtude da ação redutora dos mesmos. E' assim que os oxalatos, os citratos, os tartaratos, os orto e os pirofosfatos, os arseniatos, os cianetos, os fluoretos, os tungstatos, $\mathrm{o}$ alumínio, o antimônio, o cromo, o cobalto, o cobre bivalente, o manganez, o mercúrio bivalente, o estanho tetravalente devem, segundo MenLio, eliminar-se da solução em que se vai dosar o ferro.

O método é, sem dúvida, valioso, mas requer separações e cuidados que o tornam laborioso e delicado.

$\checkmark$ metoao e, sem auvıaa, vanıso, mas requer separaçoes e cuıaaaos que o tornam laborioso e delicado. 


\section{Rubens Salomé Pereira e J. Onofre Araujo - O Ferro em Biologia \\ METODO DO FERROCIANETO (45)}

Os sais de $\mathrm{Fe}+\mathrm{H+}$ dão, quando postos em presença do ferrocianeto de potássio, cor azul intensa, (azul da Prússia). O emprego dessa reação para fins quantitativos, por colorimetria, é muito delicado, pois mesmo em soluções extremamente diluidas, produz-se um precipitado de ferrocianeto férrico. Em presença de corpos capazes de dar precipitados ou complexos coloridos com o reativo (cobre, cobalto, nikel, manganez, etc.) a técnica de dosagem deve ser modificada de modo a eliminar-se a influência que teem. Os agentes que dão complexos com o $\mathrm{Fe}^{+++}$(oxalatos, fluoretos, etc.) (46) dificultam, perturbam, ou impedem o desenvolvimento da cor.

\section{METODO DO FERRICIANETO}

Com o $\mathrm{Fe}+$, em soluções muito diluidas, o ferricianeto dá coloração que tem sido aplicada para fins quantitativos. O processo é ainda mais delicado do que o do ferrocianeto: a concentração dos ácidos deve ser regulada; a medida da cor, que aumenta em presença de excesso de reagente, diminue sob a ação de quantidades crescentes de ácidos, e desmáia rapidamente quando em repouso, deve ser feita logo após a adição do cromogênio.

\section{METHODO DE PULSIFER (48)}

Combes mostrou que a acetilacetona dá com os sais de $\mathrm{Fe}+++$ cor vermelha, intensa, devida à formação da ferri-acetilacetona. Essa reação extremamente sensivel, permite reconhecer-se a presença de 3 microgramas de $\mathrm{Fe}+++$ Pulsifer aplicou-a à dosagem do $\mathrm{Fe}^{+++}$na água.

O método é extremamente delicado, e, se bem que estavel em condições bem determinadas, a cor não varia uniformemente em proporção com a espessura da camada colorida. E' essencial que a quantidade de ácidos livres, o excesso de reagente, o volume final das soluções sejam bem determinados.

A reação, extremamente interessante sob o ponto de vista qualitativo, não merece as mesmas referências quando se aplica a fins quantitativos.

\section{MÉTODO DO YOE E HALL (49)}

YOE (50) propôz o "ferron" - ácido 7 - iodo $-8-$ hidroxiquinolina - 5 - sulfônico - para o reconhecimento do ferro, e, em 1937, Yoe e HaLl aplicaram essa reação à dosagem desse metal. JACKson (51) observa que o «ferron» é amarelo, e desenvolve, em presença do $\mathrm{Fe}+++$ cor verde adicional que não segue a lei de Lambert-Beer. Além disso, esse metodo exige que o $p H$ da solução se mantenha dentro de limites rigorosamente definidos. JACKSON não o acha muito vantajoso.

MÉTODO DE HILL (52)

Em 1898, Blau (53) mostrou que a $a-\alpha^{\prime}-$ dipiridina dá, em presença do $\mathrm{Fe}^{++}$um complexo soluvel, de cor intensamente vermelha 
Essa reação, particularmente sensivel, HiLl aplicou-a à dosagem do $\mathrm{Fe}$.

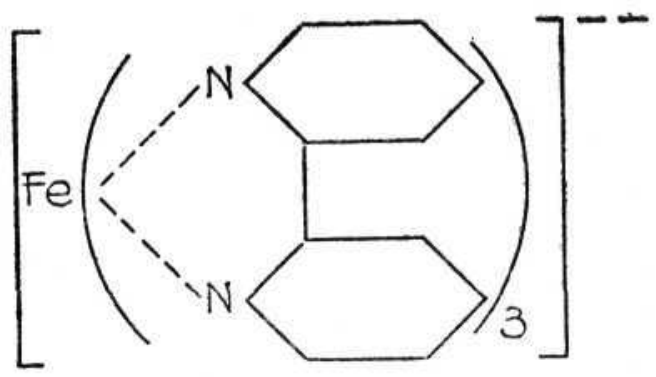

JACKSON (54), estudando o processo, verificou que os pirofosfatos impedem que a cor se desenvolva normalmente, pois só depois de 24 a 48 horas é que ela, em presença de tais compostos, apresenta a intensidade máxima. Esse investigador verificou que o aquecimento, durante 18 horas à temperatura de $80^{\circ} \mathrm{C}$, da solução das cinzas, permite que a cor do complexo alcance o ponto máximo alguns minutos, apenas, depois da adição da $\alpha-\alpha$ - dipiridina ao soluto em que se encontra o ferro. Essa pequena modificação consentiu que esse pesquisador obtivesse resultados concordantes em determinações do $\mathrm{Fe}$ feitas em diferentes partes alíquotas da mesma solução de cinzas de certos produtos (cereais, v. g..). Em outros casos, porem (espinafre, v. g.), porções diversas dos mesmos solutos acusavam, analisadas, percentagens diferentes, do mesmo corpo, e os números obtidos eram tanto menores quanto maiores fossem as alíquotas medidas. Essa anormalidade, atribuiu-a JACKSON à formação de substâncias perturbadoras durante a incineração, e para eliminar essa causa de erro, ele propõe o isolamento do ferro sob forma de sulfureto, de acordo com a técnica resumida a seguir:

1) incineração sulfo-nitro-perclorica

2) neutralisação pelo amoníaco, em presença do bromofenol

3) alcalinisação pelo amoníaco e precipitação pelo gás sulfídrico

4) filtração e dissolução do precipitado de sulfureto de ferro

5) eliminação do excesso de gás sulfídrico

6) neutralisação cuidadosa da solução ácida de sorte que esta, neutralisada, permaneça límpida

7) adição do tampão "acetato de sódio - ácido acetico», da hidroquinona e da $a-\alpha^{\prime}$ - diripidina.

E' ocioso lembrar a extrema delicadeza dessa marcha analítica, bem demonstrada pelo fato de ser indispensavel não haver oxidação alguma do sulfureto de ferro precipitado, pois, nesse caso, a perda da análise é inevitavel.

JACKson recomenda que da solução em que se vai dosar o ferro se tome tal parte alíquota que nesta se encontrem cerca de 10 microgramas de $F e$. Para medir a intensidade da cor ele usou o colorímetro fotoelétrico, de Evelyn.

\section{METTODO DE LAVOLLAY (55)}

Depois dos trabalhos de Berg (56) sobre os complexos da 8-hidroxiquinolina, este reagente tem sido aplicado à determinação de vários corpos. Em 1934, Javillier e Lavollay (57), estudando os complexos metálicos da 8- 
hidroxiquinolina, observaram que o composto férrico, insoluvel em meio aquoso, se dissolvia em solventes orgânicos, como o alcool, p. ex., e dava solução verdeazulada. Baseado nos estudos então feitos, LAvollay propoz, em 1935, um método colorimétrico para a dosagem do ferro.

A formação do complexo soluvel é função da acidez do meio: em solução fortemente ácida ele se dissocia, e em meio alcalino o ferro se precipita sob forma de hidróxido. Para se obter cor rigorosamente reprodutivel, é necessário operar em condições tais que a acidez seja bem definida.

A cor é estavel durante muitas horas, e a reação é muito sensivel.

\section{MÉTODO DE SAYWELL E CUNNINGHAM}

BLAU (59), no seu trabalho sobre complexos, mostrou que a $o$-fenantrolina dá, em presença do $\mathrm{Fe} e^{++}$, um corpo soluvel intensamente corado. Os complexos formado pela $o$-fenantrolina, e pela $a-\alpha^{\prime}-$ dipiridina, com o $\mathrm{Fe}++$ apresentam caraterísticos que muito se assemelham, e SAYweLl e CUNNINGHAM propuzeram a reação de BLAU para a determinação desse metal em suco de frutas e em outros produtos.

Hummel e Willard (60), com o fito de aplicar o processo à dosagem do ferro em materiais metabólicos que, quasi sempre, são ricos de fósforo, modificaram a técnica de Saywell e Cunningham: eles reduzem o $\mathrm{Fe}^{+++}$a $\mathrm{Fe}^{++}$por meio da hidroquinona em solução de $\mathrm{pH}=4,5$ e fazem a cor desenvolver-se em meio ácido, de $\mathrm{pH}=3$ ou 4 .

De acordo com Hummel e Willard, podem-se determinar, com erro de $3 \%$, por meio do fotelômetro, quantidades compreendidas entre $0.01 \mathrm{mg}$. e $0.70 \mathrm{mg}$. de $\mathrm{Fe}$, e pelo colorímetro, com igual segurança, $0.2 \mathrm{mg}$. a $0.5 \mathrm{mg}$. Os elementos de que comumente se acham traços nos materiais biológicos com exceção do cobre em quantidades superiores a $0.2 \mathrm{mg}$, e do estanho em porções mais altas do que $0.6 \mathrm{mg}$. - não exercem ação prejudicial.

Fortune e Mellon (61) fizeram um estudo crítico dos fatores que interveem na formação do complexo corado. Esses pesquisadores acham que a cor é estavel durante 15 dias pelo menos, e usam, como o fizeram SAYwell e Cunningham, para fins de redução, o cloridrato de hidroxilamina, por ser este de todos os redutores experimentados, o mais satisfatório. Do $\mathrm{pH}$ da solução muito depende a influência de vários ionios, e à formação de complexos do ferro, mais estaveis do que o formado com o-fenantrolina, se deve, provavelmente, a ação perturbadora de certos corpos. Algumas interferências se originam da produção de compostos insoluveis, do reagente; outras, da própria cor do ionio prejudicial.

O método da o-fenantrolina apresenta duas vantagens impreciaveis: grande sensibilidade e indiferença à ação da maioria dos ionios comumente presentes nos meios biológicos.

ForTune e MELlon empregaram, para medir a cor, o espetrofotometro fotoelétrico descrito por Michaelson e Liehafsky, e obtiveram alto grau de precisão.

\section{MÉTODO DE HOWE E MELLON (62)}

EPHRAim (63) encontrou na salicilaldoxima $-\mathrm{C}_{6} \mathrm{H}_{4}(\mathrm{OH}) \mathrm{CHNOH}-$ um reativo específico do cobre que, em meio acético, dá um precipitado 
de cupri-salicilaldoxima, complexo, dificilmente soluvel, que muito bem se presta para fins quantitativos, A maior parte dos ionios metálicos só se precipitam em
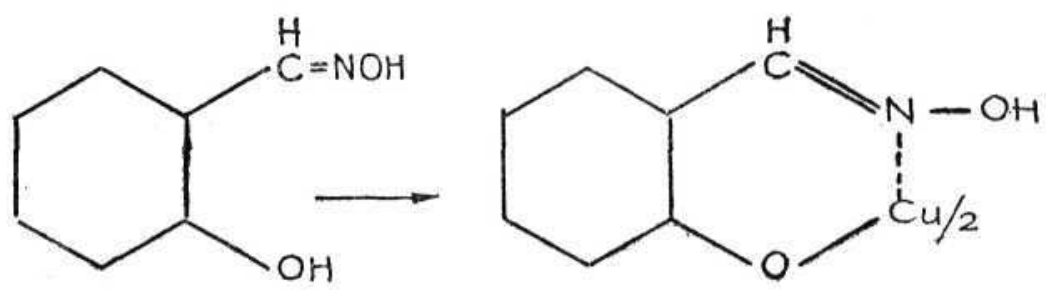

solução neutra, ou levemente alcalina. Por exceção, o paládio e o ouro dão, em meio acético, precipitados de $\left(\begin{array}{llllll}C_{7} & H_{6} & \mathrm{O}_{2} & N_{2}\end{array}\right) P d$ e de ouro elementar, respetivamente (64). O aproveitamento do salicilaldoxima para a dosagem do niquel, do chumbo, do paládio, foi levado a bom termo por varios investigadores (Astin e Riley, Holzer, Ishrbashi e KISHI).

O $\mathrm{Fe}+++$ forma com a salicilaldoxima um complexo colorido, soluvel, e essa reação foi recentemente proposta por Howe e Mellon, para fins quantitativos. As observações que se seguem, devem-se a esses pesquisadores.

Em meio ácido $-p H=3-$ a cor é vermelha; em alcalino $-p H=10$ -, amarela, e entre esses extremos vários matizes se sucedem, resultantes da combinação das duas cores citadas. Em solução neutra, o tom é vermelhoalaranjado. Daí resulta a necessidade de verificar-se cuidadosamente a acidez do soluto afim de este manter-se em $p H$ bem definido. Howe e Mellon escolheram a concentração de ionios $H$ correspondente a $p H=7$ aproximadamente, grau de acidez em que a cor é estavel durante 24 horas, pelo menos. Em solução acida, a cor desenvolve-se rapidamente, mas desmaia sem demora. Em meio alcalino ela requer, para alcançar pleno desenvolvimento, 15 minutos.

Os tartaratos, os citratos, os oxalatos, os cianetos, os carbonatos, os boratos, os fosfatos interferem na reação graças, provavelmente, à formação de ferri-complexos. Os redutores devem eliminar-se do meio em que se vai dosar o ferro. O chumbo, o zinco, o alumínio, o mercúrio formam, parece, complexos incolores com a salicilaldoxima, de modo que indispensavel se torna a adição de grande excesso de cromogêneo, o que, aliaz, não apresenta inconveniente algum. O cabalto, os molibdatos, os sais de uranila dão complexos corados com o reativo, e devem, por isso, estar ausentes da solução.

A reação é sensivel na proporção de $1: 20.000 .000$.

Os autores recomendam que a cor se meça em fotômetros de filtro, preferivelmente.

O método, como o apresentam Howe e Mellon, é, sem dúvida, extremamente interessante. Convem lembrar, porem, que a interferência prejudicial de vários ionios, a dos fosfatos, em particular, de que os produtos de origem biológica são, por via de regra, ricos, agravada pela influência perniciosa dos ácido-alcooes, torna absolutamente indispensavel a separação do ácido fosfórico, e isso dá ao método, especialmente em certos casos, feição laboriosa e delicada. 


\section{MÉTODO DE SALOME' PEREIRA (65)}

Lutz (66) mostrou que as soluções ácidas de $\mathrm{Fe}+++$ dão, em presença do ácido protocatéquico, cor azul-esverdeada que não se forma com o $\mathrm{Fe}++$ Este, em meio alcalino, desenvolve com o mesmo reagente, cor vermelha e dá, assim, colorido idêntico ao produzido pelo $\mathrm{Fe}+++$ quando se alcalinisa a solução em que este se encontra e na qual igualmente se acha o agente cromogêneo.

SAlomé PEReira estudou os fatores que interveem na formação das várias cores observadas, e propoz um método fotométrico de dosagem de pequenissimas quantidades de ferro. A técnica proposta pelo autor elimina a influência dos corpos habitualmente presentes nos meios biológicos - pelo menos nas concentrações em que eles geralmente se encontram em tais produtos e permite a determinação de frações de micrograma desse mètal, O processo apresenta vantagens inestimaveis, como sejam grande sensibilidade, indiferença à ação de quase todos os ionios comumente encontrados nos produtos do origem biológica, e à forma em que se acha o ferro - se bi ou trivalente donde se conclue não haver necessidade, para dosar-se o ferro total, de trabalho preliminar de oxidação, ou de redução. As quantidades extremamente reduzidas, que se podem determinar quantitativamente por esse método, consentem que ele se possa empregar não só nas análises de rotina, e nas de pesquisas biológicas, mas tambem nas destinadas à verificação da pureza dos reagentes. $O$ processo sobre ser muito sensivel, é simples, rápido e exato.

\section{III}

\section{O FERRO SERICO}

Durante muito tempo, a presença do ferro não hemoglobínico no soro, foi posta em dúvida. O cepticismo plenamente se justificava pelo perigo permanente de hemólise, e pelas reduzidíssimas quantidades encontradas. O mérito de haver demonstrado a existência de tal forma de ferro sérico, cabe a FOnTÈs e Thivolle (67) que, empregando $500 \mathrm{cc}$ de soro de cavalo, usando o processo nitro-magnesiano de incineração, e aplicando método próprio - o molibdo-manganimétrico - de dosagem, acharam, em duas determinações consecutivas, $1,92 \mathrm{mg} /$ e $2,08 \mathrm{mg} / \mathrm{de} \mathrm{Fe}$ por litro. Como, em período de regeneração hemática, houvessem encontrado números mais baixos $-1,12 \mathrm{mg}$. e $0,916 \mathrm{mg}$. por $1000 \mathrm{cc}$ - concluiram que, na hematopoiese ativa, a quantidade de ferro destinada à regeneração globular se reduz à metade, o que se deve, provavelmente, à retençâo mais enérgica por parte dos orgãos que asseguram tal regeneração. Esses pesquisadores, que não procuraram, no citado trabalho, determinar a natureza dos compostos do ferro circulante, reconheciam as dificuldades apresentadas pelo problema da separação das demais, da forma hemoglobínica do ferro. 
Sob o ponto de vista puramente químico, os compostos biológicos do ferro assim se podem classificar (68):

1) compostos heme, ou hemínicos, tais como a hemoglobina, o citocromo, o fermento respiratorio, etc.;

2) compostos não heme, ou não hemínicos, em que se incluem todos os demais, de natureza ainda mal definida até a hora presente.

Admite-se geralmente, hoje, a presença, no sangue, de tres formas do ferro, alem da que faz parte do mecanismo do fermento respiratorio: hemoglobínica, sérica e facilmente liberavel - leicht $a b$ spaltebares Bluteisen, de BARKAN.

BARKAN e LINTZEL, trabalhando independentemente, verificaram que o sangue submetido à influência da pepsina e dos fermentos pancreáticos, liberta, isto é, ionisa $5 \%$ a $10 \%$ do ferro que nele se encontra. Essa atividade liberativa é tambem exercida pelos ácidos e pelas bases diluidos, como foi observado pelos mesmos pesquisadores. Lintzel e RADEfF (69) lidando com hemoglobina cristalizada, conseguiram ionisar tambem esse "ferro facilmente liberavel», e daí concluiram que ele provinha do desdobramento da molécula desse pigmento. BARKAN, discordando, nesse ponto, de Lintzel, pensa que a referida forma constitue terceiro tipo de ferro sanguineo, e a essa conclusão chegou devido, entre outros, ao fato de haver conseguido ionisar apenas traços desse metal, de preparações, conservadas constantemente em alcool, de hemoglobina cristalizada e submetida à ação do ácido clorídrico diluido.

BARKAN e BERGER dividiram o «ferro facilmente liberavel» em duas frações:

$E$, que compreende $60 \%$ a $70 \%$ do total, e que se acha apenas nos eritrocitos.

$E^{\prime}$, que encerra os restantes $30 \%$ a $40 \%$, e que se encontra no soro e na hemácia.

$O$ ferro da fração $E$ liga-se de tal sorte ao monóxido de carbono que se protege contra a ação liberativa dos ácidos diluidos. Acredita-se que a capacidade de união com o monóxido de carbono seja maior nessa fração do que na própria hemoglobina, de sorte que, no caso de saturação parcial do sangue pelo $C O$, este se liga com maior percentagem de ferro dessa parte do facilmente liberavel do que com o do próprio pigmento. Schwartz e Deckert, e Olesk observaram que o $\mathrm{CO}$ absorvido pelos fumantes inveterados é su- 
ficiente para subtrair parte do ferro facilmente ionisavel à ação dos ácidos diluidos.

Na fração $E^{\prime}$ o ferro não se combina com o monóxido de carbono, e como se encontra na hemácia e no soro, todo o $\mathrm{Fe}$ que neste se acha é, na realidade, metal que a ela pertence.

Para Barkan e Schales $(70)$ as duas frações $-E$ e $E^{\prime}-$ são cromoproteinas da natureza da hemoglobina, nas quais a proteina é provavelmente a globina inalterada, e o grupo prostético é um derivado hemínico em que o anel porfirínico se acha aberto. Os mesmos investigadores propuzeram o nome de pseudohemoglobinas para tais cromoproteinas, e o de pseudoheme, ou pseudohemina, para os grupos prostéticos de tais compostos. Os «verdadeiros» corpos diferem dos «pseudos» pelo fato de estes apresentarem o anel porfirínico aberto em ponto designado pela letra grega apropriada. Assim, a fração $E$, que se constitue de globina e de pseudoheme em que o ponto de rutura do anel se acha no grupo metina a, e cujo ferro é, como na hemoglobina, bivalente chamar-se-à $\alpha-$ pseudohemoglobina. A fração $E^{\prime}$, em que o metal se encontra na forma trivalene, classificar-se-à de a - pseudomethemoglobina. A perda do metal e da globina faz que as pseudohemoglobinas se transformem em pigmentos biliares, de que a bilirubina é o produto final. Ambas as frações $-E$ e $E^{\prime}$ - acompanham a hemoglobina dos eritrocitos circulantes, e são pontos de transição na série de fenómenos que marcam a transformação da hemoglobina em bilirubina.

Tais são, em linhas gerais, as idéias de Barkan e Schales.

BARKAN e WALKer (71) pensam que os produtos intermediários - pseudohemoglobinas - resultam da ação do peróxido de hidrogênio nascente, sobre a hemoglobina, o que, por seu turno, em presença de oxigênio, dá origem a certas substâncias redutoras (ácido ascórbico v. g.) e a certos catalizadores não específicos. A formação de um pigmento biliar ferro-globínico (LEMBERG) à custa da hemoglobina na presença do ácido ascórbico e do oxigênio, tida por BARKAN e WALKER como exemplo de processo provavelmente geral, vem em auxílio da teoria exposta. A bilirubina, o ferro e a globina são produtos do desdobramento das pseudohemoglobinas, corpos relativamente instaveis, e a rutura dessas moléculas se realiza dentro das hemácias, sem a intervenção de mecanismo enzimático. 
Para esses pesquizadores, a tendencia da bilirubina de combinar-se especificamente com a soroalbumina, e a do ferro, de ligar-se á soroglobina, devem exercer influência sobre a passagem dessas substâncias das hemácias para o plasma, o que, em absoluto, não se faz por simples difusão.

BARKAN e WALKER demonstraram o transporte simultâneo do ferro e da bilirubina das células vermelhas para o plasma, in vitro, e verificaram que ambos passam em quantidades semelhantes, havendo, em geral, leve excesso, apenas, do metal. Eles notaram, ainda, que a velocidade dessa passagem é variavel, e que as quantidades medidas não explicam a formação diária total do pigmento biliar, pois ao passo que apenas se formariam $15 \mathrm{mg}$. pelo mecanismo descrito. WATSON calcula que a produção, por dia, de urobilina se eleve a $150 \mathrm{mg}$.

Para BARKAN e WaLKer, a maior parte do pigmento não se forma no sangue circulante. Pensam eles que as pseudohemoglobinas são estados intermediários entre a hemoglobina e a bilirubina, qualquer que seja o local em que a degradação se processe.

Confirmando a hipótese lançada, esses pesquizadores (72) verificaram que a quantidade de ferro pseudohemoglobínico é, por via de regra, maior nas células de menor resistência osmótica, as quais, admite-se, são as mais velhas, o que demonstra que a percentagem de ferro pseudohemoglobínico - e consequentemente a de pseudohemoglobinas - varia no mesmo sangue. Com efeito, considerando-se que a abertura do anel porfirínico seja provocada por oxidação produzida pelo peróxido de hidrogênio nascente e que este seja um produto do mecanismo de oxi-redução celular, a hipótese de BARKAN exige, como elemento de prova, que as hemácias mais velhas contenham maior quantidade de pseudohemoglobinas do que as mais novas. Admite-se geralmente que o decréscimo da resistência osmótica seja propriedade dos eritrocitos que envelhecem.

MOORE e colaboradores (73) (74) concluem dos excelentes trabalhos feitos, o que assim se resume:

1) é de transporte o ferro sérico de que a quantidade se influencia pelos fatores seguintes, que se podem medir por ele:

a) quantidade de ferro absorvido pelo trato gastro-intestinal

b) grandeza e aproveitamento das reservas corporais, de ferro 
c) capacidade da medula, de utilizar esse metal na síntese da hemoglobina

d) velocidade dessa síntese

e) grandeza da hemólise que se produz no baço e em outros orgãos

f) equilibrio fisiológico - ou patológico - existente entre a velocidade da síntese da hemoglobina e a hemólise

2) a função fisiológica do "ferro facilmente liberavel» ainda aguarda ser definida.

- Como se vê, o ferro sérico, estudado inicialmente a título de simples curiosidade fisiológica, toma tal importância biológica que as pesquizas a seu respeito, sobre necessarias, se tornam urgentes. Interesse crescente pelo mecanismo de transporte desse metal na corrente sanguínea, justifica-se pela necessidade de se compreender melhor essa fase do metabolismo desse elemento, o que, conseguido, poderá esclarecer os fenómenos da hematopoiese normal, e os da deficiência férrica.

- Depois dos seus notabilíssimos trabalhos sobre a estrutura das porfirinas, HANS FiSCHER demonstrou que a posição relativa dos grupos que se situam em cadêia lateral nos núcleos do pirrol, ao substituirem o hidrogênio dos átomos de carbono numerados de 1 a 8 na porfina, permite que se preveja a existência de vários isômeros. E' assim que a coproporfirina, em que há dois grupos de substituição diferentes - metílico e propiônico - fornece quatro isômeros, já obtidos, aliás, por via sintética, e que são:
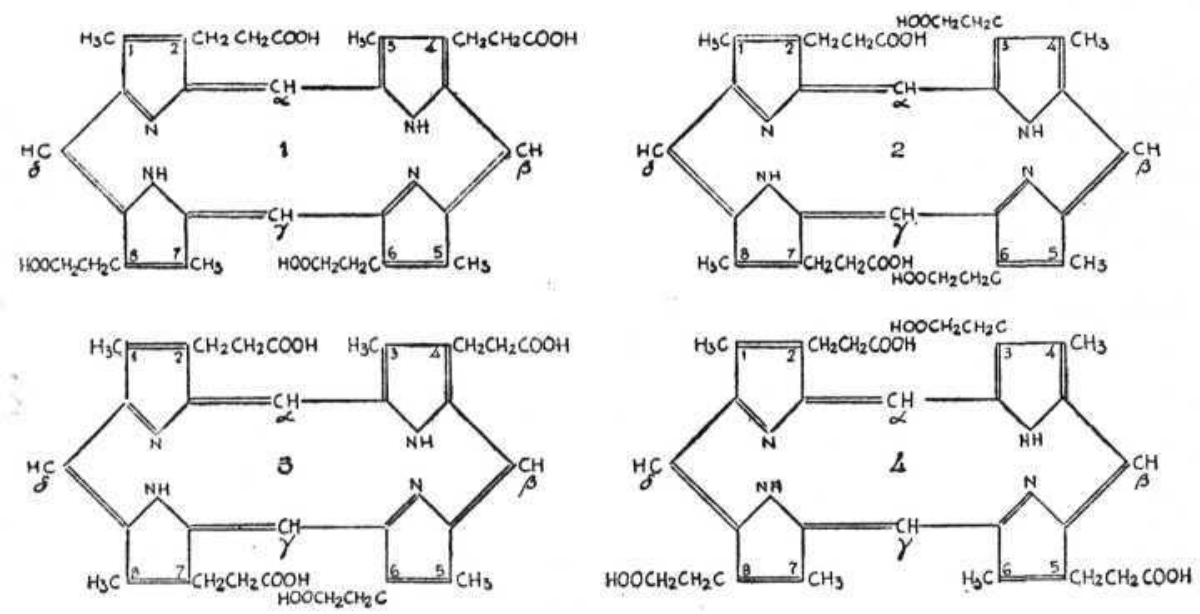
Fato digno de nota é o de a natureza produzir apenas pigmentos que se filiam ao tipo 1 , ou ao 3 . No homem, o sanguíneo pertence ao 3, mas em certos casos patológicos, as porfirinas eliminadas podem ser da forma 1. Como a redistribuição dos grupos que tomam o logar do hidrogênio porfínico é necessaria para se passar de um isômero a outro, e como isso equivale a uma resíntese, não se crê que o organismo realise esse trabalho: o provavel é que os mecanismos formadores desses isômeros sejam independentes um do outro. No homem, as porfirinas do tipo 1 se formam, em determinados casos mórbidos, por via sintética nos orgãos hematopoiéticos, já tendo sido observada a sua presença na medula. E' de notar-se que ainda não se achou no organismo uma só metalo-porfirina de estrutura 1.

As porfirinas do tipo 3 , a que pertencem os complexos metálicos, se formam por via sintética, fato demonstrado por Duesberg, e no caso de certos desvios da formação da hemoglobina (anemia, v. g.), a medula produz grande quantidade delas que, não se combinando, em larga parte, à globina e ao ferro, se eliminam.

Thomas (75) numa série interessantíssima de estudos sobre as porfirinas em biologia e em patologia, chama a atenção para o fato de a excreção de tais corpos não constituir prova de hiperatividade hematopoiética, e para o de ser necessario precisar o tipo isomérico antes de se poder interpretar o fenômeno. Aquí, porem, surgem dificuldades de ordem prática. O estabelecimento da fórmula estrutural dos vários isômeros requer a verificação do ponto de fusão do ester metílico, ou a determinação da curva de fluorescência em função do grau de acidez - e isso exige quantidades relativamente consideraveis, de material.

THOMas verificou que a hemólise sem intoxicação, provocada pela injeção de agua distilada por via endovenosa, e que a introdução de hemoglobina, ou de hematina, no rato normal, afim de examinar os efeitos da desintegração massiça da hemoglobina sem provocar fenômenos de intoxicação pelos agentes hemolisantes, e para evitar estímulo da atividade hematopoiética, de compensação, o que se poderia dar no caso de se provocar desdobramento do pigmento do próprio animal - originam a desintegração do cromogêneo, o aparecimento de pigmentos biliares e forte eliminação de urobilina e de, sobretudo, estercobilina, sem que se note variação da quantidade de porfirina espelida. A intoxicação pelo fósforo, pelo chumbo, determina eliminação alta de porfirina, que mais ainda se alteia pela injeção de hemoglobina em doses fortes. A desintegração do pigmento sanguíneo e a formação de bilirubina se realisam, em condições 
fisiológicas normais, sem libertação de porfirina, de acordo, provavelmente, com o mecanismo estudado por LEMBERG.

A fórmula da bilirubina estabelecida por Fischer (76) mostra que ela provem do núcleo porfirínico da hemoglobina, por meio de oxidação: o grupo «metina $a$ » é substituido por dois hidroxilos, e assim se abre o anel porfirínico. Se essa reação conduz à bilirubina, o grupo «metina $\gamma$ » se reduz a $\mathrm{CH}_{2}$. Para Lemberg, forma-se primeiramente a biliverdina, que se reduz a seguir. Isso está de acordo com o fato de o fígado reduzir a biliverdina a bilirubina, o que foi observado por BarRY e Levine (77). Na bilis de certos animais (rã) encontra-se a biliverdina, e não se acha a bilirubina.

As biliverdinas formam ferricloretos, como o demonstraram FISCHER e seus colaboradores (78). LEMBERG estudou detidamente o ester verdohemínico de WARBURG e Negelein (79), caraterizou as verdoheminas como hemocromogêneos piridínicos das isobiliverdinas e para elas propôs o nome de verdohemocromogêneo.

Ao contrario dos ferricloretos biliverdínicos, as verdoheminas ainda manteem o ferro em combinação complexa e são, como o demonstrou Lembero (80), complexos do $\mathrm{Fe}^{++}$em que a piridina se liga ao metal que se acha na forma «facilmente liberavel». Esse mesmo pesquisador indicou a presença, nas verdoheminas, de cadêia aberta, mantida em posição, todavia, pelo átomo central, de ferro, e concluiu das investigações feitas, que esses compostos são hemocromogêneos dos pigmentos biliares, em que o anel se acha aberto. O composto livre de ferro não é, provavelmente, idêntico à biliverdina, mas, instavel, nesta facilmente se transforma.

O mecanismo da transfirmação da hemoglobina em bilirubina é, segundo Lemberg, o seguinte:

a) rutura, por oxidação, do anel porfirínico no grupo «metina $a \gg$

b) formação dum pigmento - o verdohemocromogêneo - em que ainda se acham a globina e o ferro

c) transformação do verdohemocromogêneo, por perda da proteina e do metal, em biliverdina e, finalmente, em bilirubina 
Essas mudanças assim se podem formular:

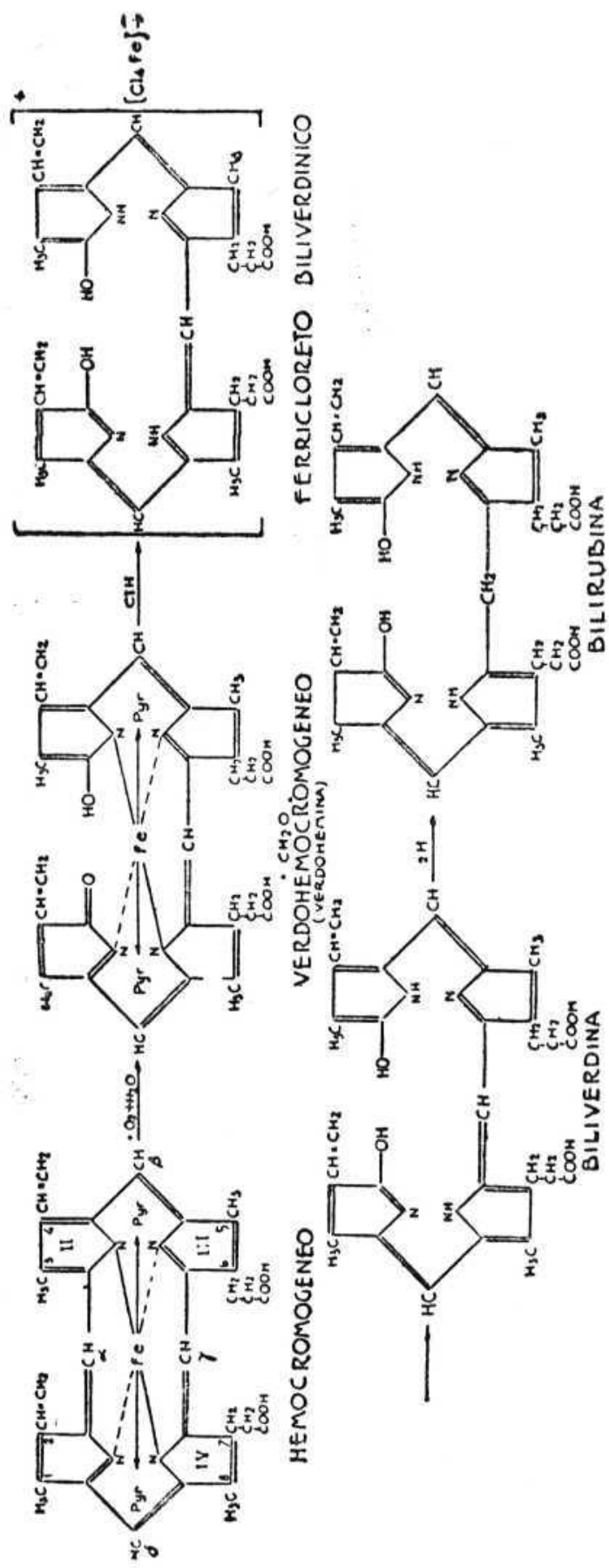

A abertura do anel transforma o hemocromogêneo em um núcleo de pigmento biliar, e a estabilidade do complexo decresce. Como nos hemocromogêneos, enquanto o ferro central mantiver os seus seis pontos de coordenação satisfeitos, o anel, apesar de aberto, conserva a sua forma no verdohemocromogêneo. O ácido clorídrico remove a piridina e o verdoheme se oxida e se transforma em verdohemina a qual, por seu turno, se desdobra em $\mathrm{Cl}_{3} \mathrm{Fe}$ e isobiliverdina que se isomerisa, transformando o azoto do núcleo pirrólico III em azoto terciario básico, e dá por fim a bilirubina.

No organismo, à vista de a hemoglobina ser o composto oxidado - e não, como no modelo acima, o hemocromogêneo piridínico - o composto verdohemico é a verdohemoglobina, ou a verdohemocromogeneoglobina. A hidrazina - redutor usado nas pesquizas descritas se substitue, no ser vivo, por um sistema enzimático, de ação redutora. Quanto à oxidação, não é necessário fazer intervir a ação de fermentos especiais, pois o heme da própria molécula hemoglo- 
binica, ou do citocromo, age como catalisador. O trabalho de LEMBERG mostra que a formação dos pigmentos biliares no organismo é a consequência natural da ação catalítica do ferro hemico sobre a propria molécula do heme.

As reações descritas se obteem facilmente in vitro, pelo tratamento do hemocromogêneo piridínico pelo ácido ascórbico: forma-se o verdohemocromogêneo em que o ferro se encontra sob forma «facilmente liberavel» e, portanto, separavel pelo ácido clorídrico diluido. Consegue-se, assim, a biliverdina que, hidrogenada, dá a bilirubina. Os estados intermediários dessa transformação - hemoglobina bilirubina - foram encontrados por LEMBERG no organismo, o que mostra que o mecanismo descrito corresponde ao da evolução fisiológica normal do pigmento sanguíneo, e confirma as observações de Thоmas em relação ao fato de mesmo doses massiças de hemoglobina não darem, ao desintegrar-se no corpo, origem à eliminação de porfirina. Um dos pontos característicos dessa desintegração é, como se vê, a ruptura do anel porfirínico, o que exclue a possibilidade de se eliminar, ulteriormente, o núcleo tetrapirrólico.

A sintese das porfirinas, que se realiza nos orgãos hematopoiéticos, se prolonga, por via de regra, na formação das ferro-porfirinas. Acidentalmente, devido a intoxicações por certos metais, como o chumbo, p. ex., ou a desvios do metabolismo dos pigmentos, pode suceder que parte variavel da porfirina sintetizada não se combine com o ferro, e permaneça livre. Essa fração se elimina após se haver carboxilado, fenômeno verificado por VAN der BERGH e seus colaboradores. Em certos estados morbidos, observa-se tambem a formação duma porfirina isômera da que se encontra no grupo prostético da hemoglobina, incapaz de ligar-se ao ferro e, portanto, de formar a hematina. Essa porfirina se carboxila e se elimina, dando a copro e a uroporfirina que, neste caso, são isômeras das normais.

THomas evidenciou a existência dum mecanismo especial, de desintegração que, quando em exercício, liberta a porfirina inalterada. Como vimos, o processo normal de desintegração porfirínica se inicia pela oxidação do núcleo tetrapirrólico seguida da rutura do mesmo num dos grupos metina, o que exclue a possibilidade de re-síntese da porfirina. Esse pesquizador verificou que a hematina depois de haver passado por uma série de oxidações e de reduções alternadas, pelo ferricianeto e pelo hidrosulfito - hematina modificada, ou hematina $c$, de Roche e BÉNEvent (81), cujo ferro é facilmente separavel não sofre cisão no organismo. In vitro ela não é oxidavel, não dá, em presença do oxigênio e do ácido ascórbico, origem ao verdohemocromogêneo, ao passo que a hematina «normal» o faz facilmente. 
Thomas pensa que, no organismo, a via preferencial de desintegração do citocromo $c$ seja a que se adata ao mecanismo que acabamos de citar. A cisão originada pela oxidação do núcleo tetrapirrólico, tão facilmente verificavel no caso da hemoglobina, dificilmente se observa no citocromo $c$ que, em compensação, se decompõe com facilidade em meio fracamente ácido, e o ferro se elimina sem que se rompa o anel porfirínico. $\mathrm{O}$ citado pesquisador verificou que o citocromo, injetado no animal por via hipodérmica, se desdobra e dá uma porfirina que é a típica citocrômica, descrita por HiLl e KeILIN.

Como em meio ácido as radiações violetas, em particular, muito favorecem a libertação do ferro dos complexos hemínicos, é bem possivel que a luz intervenha nos fenómenos do metabolismo dos pigmentos ferro-porfirínicos ao nivel dos tecidos cutâneos, por via catalítica.

IV

\section{DETERMINAÇÃO DO FERRO SÉRICO}

Experiências feitas com cães (82) mostraram que o nivel do ferro sérico é ordinariamente constante nos animais mantidos em jejum, e que a percentagem desse metal no soro se eleva em seguida à administração de sais minerais de ferro, quando se obteem números tres ou quatro vezes mais altos, que decrescem lentamente até volverem ao nivel inicial - o do jejum - após algumas horas decorridas. Fenômeno semelhante se dá com o homem (83).

O ferro sérico representa o absorvido pelo intestino, e que se transporta pelo sôro, e o resultante da decomposição da hemoglobina e de outros compostos hemínicos, que se dirige para o sistema hematopoiético, ou para os tecidos. De acordo com o que hoje se sabe, é provavel que o ferro sérico meça o metabolismo desse metal. Em casos de grande hemorragia, entre nós Araujo achou taxas extremamente baixas.

O estudo do ferro sérico transcende, como se vê, de simples curiosidade fisiológica, e surge como problema de alta significação biológica.

A determinação do ferro sérico é, devido às baixíssimas taxas encontradas, à necessidade, por vezes muito comum, de se restringir o volume do sôro empregado na análise, e ao perigo permanente de hemólise, assunto de particular delicadeza. A eliminação completa da hemoglobina é condição indispensavel ao bom exito do trabalho, e deve ser realizada, seja pelo preparo de soro perfeitamente isento dela, como o procuram fazer Fowweather (84), Moore, e outros, seja pela precipitação e consequente separação de todo o hemocromo- 
gêneo porventura existente no material, como o fizeram BARKAN (85), (86) (87), Heilmeyer, Lederer e Maesschalck (88), etc..

MOORE, modificando levemente a técnica de Fowweather, recolhe o sangue num tubo de centrifugação parafinado, centrifuga-o de pronto à velocidade de 2500 rotações por minuto, durante $3 / 4$ de hora. Esse investigador notou que, mesmo em casos em que se tomavam todas as precauções, a hemólise se produzia, especialmente quando a centrifugação não se seguia imediatamente à colheita do material.

Tomando-se, para calcular-se a hemoglobina a partir do ferro, o fator 0,336 , como o faz BARKAN, e $10 \mathrm{cc}$ a $15 \mathrm{cc}$ de soro para a determinação, como o indica Moore, e sabendo-se que o ferro sérico existe em quantidades que normalmente variam entre 50 e 180 microgramas de $\mathrm{Fe}$ por $100 \mathrm{cc}$, verifica-se que basta haver $1,5 \mathrm{mg}$. a $5,4 \mathrm{mg}$. de hemoglobina nos $10 \mathrm{cc}$ para que só o metal do hemocromogêneo presente equivalha a todo o que normalmente se acha no soro.

Bing e HANZAL, incapazes de reproduzir os resultados conseguidos por FOWWEATHER, declaram ser indispensavel descobrir-se meio de medir a hemoglobina existente, e para tanto propõem um processo baseado na cor que, sob certas condições, a benzidina dá com esse pigmento. Acontece, porem, que apenas $75 \%$ da hemoglobina ajuntada ao soro pode ser assim recuperada. E', pois, necessario estabelecer-se, para cada série de determinações, um "fator de recuperação», o que dá ao método feição laboriosa, delicada, e o torna passivel de grave causa de erro.

MOORE, seguindo o caminho indicado por Bing e Hanzal, dosa pela benzidina a hemoglobina presente no soro, deduz o ferro que nela se acha e faz esse fator de correção entrar no cálculo da percentagem do ferro sérico. A delicadeza desse modo de operar, e as causas de erro dele decorrentes são reconhecidas e discutidas pelo próprio MOORE.

A obtenção de soro livre de hemoglobina é tarefa quase irrealisavel pois, como o observa LEDERER, basta exercer pressão um pouco mais forte ao aspirar, ou ao expelir, o sangue para que a hemólise se dê. Essas dificuldades extremamente sérias levaram outros investigadores a eliminar o pigmento por meio da desproteinisação pelo ácido tricloracético. Fowweather, e depois Tompsett (89), entre outros, fizeram a essa técnica duas objeções de monta, a saber:

a) o ferro sérico é, desse modo, considerado como não proteico, e isso não se acha demonstrado. 
b) apreciaveis quantidades de verdadeiro ferro sérico se arrastam, talvez por processo de coprecipitação, pelo volumoso precipitado que se forma, e escapam, assim, à dosagem.

Essas críticas muito sérias mereceram toda a consideração dos investigadores interessados no assunto. BARKAN verificou que o ácido clorídrico diluido ionisa todo o ferro sérico a que a hemoglobina, posta nas mesmas condições, não liberta o seu. HeILMEYer, para verificar a segurança do processo, dosoll o pigmento presente no soro, calculou o ferro dele proveniente, determinou em seguida o ferro «facilmente liberavel» e, por fim, o total. Os resultados obtidos

$\mathrm{Fe}$ hemoglobinico $+\mathrm{Fe}$ facilmente liberavel $=\mathrm{Fe}$ total mostram que:

1) o ácido clorídrico diluido liberta todo o ferro sérico

2) o ferro «facilmente liberavel» representa a totalidade do ferro sérico

O processo de desproteinisação tricloracética é, pois, seguro.

- Os métodos químicos destinados à determinação de quantidades pequeníssimas de ferro são, como o vimos, numerosos, mas nem todos se prestam bem ao fim que temos em vista, quer por não apresentarem suficiente sensibilidade, quer por se sujeitarem a numerosas influências prejudiciais, quer, ainda, por serem de execução laboriosa e delicada.

Para a dosagem desse metal no soro, os processos que maior aceitação teem tido são o do tiocianato, o do ácido tioglicólico, o da $a-\alpha^{\prime}-$ dipiridina e, ultimamente, o da $o-$ fenantrolina. A extrema sensibilidade do método do ácido protocatéquico, publicado recentemente; o fato de, nas condições descritas, tanto o $\mathrm{Fe}^{+++}$como o $\mathrm{Fe}^{++}$se comportarem de modo idêntico, de maneira a tornar desnecessário trabalho prévio de redução, ou de oxidação; a grande simplicidade da técnica indicada, levaram-nos a aplicá-lo à determinação do ferro sérico.

\section{MÉTODO}

A dosagem do ferro sérico encerra as três fases seguintes:

1) ionisação do ferro

2) desproteinisação do soro

3) determinação do metal presente no liquido resultante do tratamento anterior. 


\section{1 \\ IONISAÇÃO DO FERRO}

BARKAN demonstrou que a incubação do soro em presença do ácido clorídrico diluido, à temperatura de $37 \circ \mathrm{C}$, durante certo tempo, permite que se determine o ferro no líquido incolor e límpido obtido pela desproteinisação pelo ácido tricloracetico, ou pela ultrafiltração, sem que se verifiquem as perdas mencionadas por FowwEATHER, TOMPSETT, e outros. Várias têm sido as concentrações de $\mathrm{ClH}$ indicadas. No presente trabalho empregamos $\mathrm{ClH} 0.2 \mathrm{~N}$, pois mesmo no caso do sangue total, variações entre $0.1 \mathrm{~N}$ a $0.3 \mathrm{~N}$ não alteram os resultados, e assim procedemos:

Em tubos de centrifugação de $10 \mathrm{cc}$ de capacidade util, graduados à altura de $1 c c, 2 c c, 3 c c, 4 c c, 5 c c$ e $6 c c$, põem-se volumes de soro compreendidos entre $0.5 \mathrm{cc}$ e $3 \mathrm{cc}$, exactamente medidos; ajuntase, então, $\mathrm{ClH} 0.2 \mathrm{~N}$ em quantidade igual à metade da de soro empregada na análise; arrolham-se os tubos e colocam-se na estufa regulada a $37^{\circ} \mathrm{C}$ durante, no mínimo, duas horas. Se o período de incubação puder ser mais longo, espaço de tempo conveniente é o que se compreende entre 16 e 24 horas. BARKAN recomenda uma hora, no mínimo; em geral, porem, ele deixa na estufa durante a noite, a incubar.

Os tubos resfriam-se, em seguida, à temperatura ambiente.

2

\section{DESPROTEINISAÇÃO DO SORO}

Ao soro ácido, resfriado, ajunta-se volume de ácido tricloracético a $20 \%$ igual ao de ácido clorídrico usado na ionisação do ferro. $\mathrm{O}$ desproteinisante deve ser posto às gotas, cuidadosamente, e a mistura se faz cautelosa e completamente. A altura alcançada pelo líquido que se encontra no tubo, deve corresponder a uma das graduações especificadas. Deixa-se a mistura repousar durante uma hora. Centrifuga-se, então, energicamente durante 15 minutos, à velocidade de 2500 rotações por minuto: o coágulo se separa inteiramente, e o líquido obtido, em que se encontra todo o ferro sérico, é perfeitamente incolor e límpido.

3

DETERMINAÇÃO DO FERRO PRESENTE NO LIQUIDO RESULTANTE DO TRATAMENTO ANTERIOR

A dosagem do ferro fazemo-la pelo método de Salomé Pereira e, no caso presente, empregamos para o desenvolvimento da cor, os reagentes seguintes: 
1) Ácido protocatéquico.

Num volumétrico de 100 cc põe-se $0,1 \mathrm{gr}$. de ácido protocatéquico e dissolve-se à temperatura ambiente por meio de alcool etílico

2) $\mathrm{NH}_{4} \mathrm{OH} 3 \mathrm{~N}$

a $50 \%$. Completa-se o volume com o solvente.

3) $\mathrm{SO}_{4} \mathrm{H}_{2} 3 \mathrm{~N}$

4) Mistura de $\mathrm{SO}_{4}\left(\mathrm{NH}_{4}\right)_{2} \mathrm{~N}$ (4 partes) e $\mathrm{NH}_{4} \mathrm{OH} \mathrm{N}$ (uma parte)

- Uma parte aliquota - a maior possivel - exatamente medida, do líquido desproteinisado, transfere-se para um tubo de vidro Pyrex, ou Jena, de 100 mms. x 13 mms., graduado à altura de $1,5 \mathrm{cc}$, $2 \mathrm{cc}, 2.5 \mathrm{cc}, 3 \mathrm{cc}, 3.5 \mathrm{cc}, 4 \mathrm{cc}, 4.5 \mathrm{cc}$ e $5 \mathrm{cc}$. Ajunta-se $0.1 \mathrm{cc}$ do reagente (1) e por cc do desproteinisado recolhido adiciona-se, medido por pipeta de $0.1 \mathrm{cc}$ graduada em milésimos de cc, $0.1 \mathrm{cc}$ do reativo (2). Adicionase, então, o reagente (4), gota a gota, sob constante agitação, até a cor vermelha característica desenvolver-se plenamente. Completa-se, então, com o mesmo alcalinisante, volume conveniente, marcado na parede do tubo, e que, por via de regra, deve ser o menor possivel.

Se a adição do reativo (2) determinar por si so $(0.1 \mathrm{cc})$ o aparecimento da cor característica do ferro em presença do ácido protocatéquico, o que significa estar alcalino o meio, convem acidificar levemente o líquido por meio de um traço do reagente (3) e leva-lo em seguida ao $p H$ util, pela mistura (4).

Durante todo o processo, faz-se ao mesmo tempo, sob condições rigorosamente iguais, um «branco», que servirá de líquido de compensação.

Todos os reagentes, todas as soluções devem ser preparados a partir de corpos do mais alto grau de pureza, tão isentos de contaminações - particularmente de ferro - quanto possivel.

As medidas fotométricas fazem-se no fotómetro de Pulfrich, interpondo-se o filtro $\mathrm{S} 50$ e empregando-se microcubas de $50 \mathrm{mms}$. de espessura. Lê-se a transparência, $D$, determina-se a extinção, $E$, calcula-se o coeficiênte de extinção, $k$, e pela fórmula seguinte obtem-se a concentração do ferro no soro analisado:

mg. Fe em $100 \mathrm{cc}$ de soro $=\frac{0.930 \times \mathrm{kx} \mathrm{V}}{\mathrm{v}}$

em que $V$ é o volume total da solução em que se desenvolveu a cor e $v$, o do soro tomado para a determinação. 


\section{RESULTADOS}

Afim de se verificar a reprodutibilidade dos resultados fornecidos pelo método que acabamos de descrever, fizemos no mesmo soro (de gestante) dez determinações, e os números obtidos achamse no quadro seguinte:

\begin{tabular}{c|c|c|c|c|c|c}
\hline $\begin{array}{c}\text { Volume de soro } \\
\text { tomado para a } \\
\text { análise } \\
\text { cc }\end{array}$ & $\begin{array}{c}\text { Volume de sorc } \\
\text { correspondente } \\
\text { âte aliquota } \\
\text { tomada } \\
\text { cc }\end{array}$ & $\begin{array}{c}\text { Volume final da } \\
\text { solução corada } \\
\text { cc }\end{array}$ & $\mathrm{D}$ & $\mathrm{E}$ & $\mathrm{k}$ & $\begin{array}{c}\text { Fe per } \\
\text { doo cc } \\
\text { de soro } \\
\mathrm{mg}\end{array}$ \\
\hline \hline 1.0 & 0.50 & 1.5 & 80 & 0.097 & 0.019 & 0.053 \\
1.0 & 0.65 & 1.5 & 75 & 0.125 & 0.025 & 0.054 \\
1.5 & 1.00 & 2.5 & 76 & 0.119 & 0.024 & 0.057 \\
1.5 & 1.00 & 2.5 & 76 & 0.119 & 0.024 & 0.057 \\
2.0 & 1.35 & 3.5 & 78 & 0.108 & 0.022 & 0.053 \\
2.0 & 1.35 & 3.5 & 77 & 0.114 & 0.023 & 0.055 \\
2.5 & 1.50 & 4.5 & 80 & 0.097 & 0.019 & 0.053 \\
2.5 & 1.50 & 4.5 & 80 & 0.097 & 0.019 & 0.053 \\
3.0 & 2.00 & 50 & 78 & 0.108 & 0.022 & 0.051 \\
3.0 & 2.00 & 5.0 & 77 & 0.114 & 0.023 & 0.053 \\
Média & & & & & & 0.054 \\
\hline
\end{tabular}

Para se verificar a influência de pequenas quantidades de hemoglobina no soro, fizemos quatro determinações de ferro no mesmo produto a que se ajuntou o pigmento. Os resultados veem-se no quadro a seguir:

\begin{tabular}{c|c|c|c|c|c|c|c}
\hline $\begin{array}{c}\text { Volume de soro } \\
\text { tomado para a } \\
\text { análise } \\
\text { cc }\end{array}$ & $\begin{array}{c}\text { Volume de soro } \\
\text { correspondente } \\
\text { a parte aliquota } \\
\text { tomada } \\
\text { cc }\end{array}$ & $\begin{array}{c}\text { Hemoglobina } \\
\text { ajuntada ao } \\
\text { soro } \\
\mathrm{mg}\end{array}$ & $\begin{array}{c}\text { Volume da } \\
\text { solução } \\
\text { corada } \\
\mathrm{cc}\end{array}$ & $\mathrm{D}$ & $\mathrm{E}$ & $\mathrm{k}$ & $\begin{array}{c}\text { Fe per } \\
\text { 100 cc } \\
\text { de soro } \\
\mathrm{mg}\end{array}$ \\
\hline \hline & 1.0 & 1.00 & 3.0 & 79 & 0.102 & 0.020 & 0.056 \\
2.0 & 1.0 & 1.60 & 3.0 & 80 & 0.097 & 0.019 & 0.053 \\
2.0 & 1.0 & 3.50 & 3.0 & 79 & 0.102 & 0.020 & 0.056 \\
2.0 & 1.0 & 5.80 & 3.0 & 81 & 0.092 & 0.018 & 0.050 \\
\hline 2.0 & 1.0 & &
\end{tabular}

O erro «standard» é, pois

$$
\sqrt{\frac{\Sigma\left(\mathrm{d}^{2}\right)}{\mathrm{n}(\mathrm{n}-1)}}=0.0006
$$




\section{COMENTARIOS SOBRE O MÉTODO}

A incubação previa do soro com ácido clorídrico diluido é indispensavel em todos os processos em que o ferro se vai dosar no líquido desproteinisado, como o demonstrou BARKAN; nesse caso, o ácido tricloracético pode ser usado, e as objeções de FowwEATHER e de outros, perdem o valor. O tempo mínimo de incubação é, segundo BARKAN, uma hora. Esse investigador, porem, acha preferivel deixar o ácido agir durante a noite, e assim procede quase sempre. Pessoalmente, achamos aconselhavel aumentar o espaço mínimo de tempo, de uma para duas a três horas. Em geral, porem, o período de 16 a 24 horas é o que se deve tomar.

E' de toda conveniência esperar-se que o ácido tricloracético haja pelo espaço de uma hora, antes de submeter a solução à centrifugação enérgica indicada: o líquido assim obtido é límpido e incolor.

Traços de hemoglobina não prejudicam os resultados, pois o hemocromogêneo é precipitado pelo desproteinisante. As pseudo-hemoglobinas libertam o ferro, sob a ação do ácido clorídrico diluido, de modo que os soros fortemente hemolisados dão números que não correspondem aos reais.

E' de inteira conveniência ajustar-se a acidez do líquido corado à do tampão: se a quantidade de $\mathrm{NH}_{4} \mathrm{OH} 3 \mathrm{~N}$ determinar o aparecimento da cor vẹrmelha característica, quer por não corresponderem os reagentes exatamente às concentrações indicadas, quer por ter havido engano nas medidas feitas, a cor deve ser desfeita pela menor quantidade possivel de $\mathrm{SO}_{4} \mathrm{H}_{2} 3 \mathrm{~N}$, e restabelecida logo em seguida pelo reagente (4).

Afim de evitar-se que a oxidação do ácido protocatético - o que facilmente se reconhece pelo tom amarelado que o líquido toma - falseie os resultados, é preferivel fazer-se a leitura 5 a 10 minutos depois do aparecimento da cor vermelha. Tempo mais longo pode permitir-se - 20 ou 30 minutos - mas desde que o mais leve indício de amarelo surja, no «branco» ou na solução em que se dosa o ferro, a análise deve ser repetida.

As soluções coradas devem conservar-se em local fresco, longe dos raios solares, preferivelmente no escuro. Enquanto pesquisas ulteriores não revelarem meio seguro de manter longamente a estabilidade da cor, essas precauções devem ser observadas: o ácido protocatéquico é fortemente redutor, e facilmente se oxida, particularmente em meio alcalino: desenvolve-se, então, tom amarelado que se intensifica pelo passar do tempo. 
Nas condições da técnica descrita (65), a temperatura, entre $20^{\circ} \mathrm{C}$ e $30^{\circ} \mathrm{C}$ pelo menos, não exerce ação prejudicial. E' conveniente que a solução em que se acha o ácido prototéquico não se submeta a temperatura superior a $30^{\circ} \mathrm{C}$.

Pelo presente método, todo o ferro, quer se ache como $\mathrm{Fe}^{+++}$ quer se encontre sob forma de $F e^{++}$se determina, e não há necessidade alguma de trabalho prévio de redução, como nos processos em que o complexo corado só se forma com o $\mathrm{Fe}^{++}\left(\alpha-\alpha^{\prime}-\right.$ diriridina, $o$ - fenantrolina, etc.), ou de oxidação, como nos em que só o $\mathrm{Fe}^{+++}$produz a desejada cor («ferron», salicilaldoxima, ácido salicílico, etc.).

No caso do plasma, o sangue pode ser citratado, ou oxalatado, pois, como o demonstrou Salomé Pereira, em presença desses ionios a cor, ao cabo de 8 minutos, apresenta o máximo de intensidade. O ionio fosfato, no soro, não intervem e, nas condições descritas no presente trabalho, a precaução a tomar-se, indicada pelo autor (65), de ajuntar citrato de amôneo afim de impedir-se a influência prejudicial do $\mathrm{PO}_{4}$, não se torna necessária.

Apesar do uso do "branco» para fins de compensação, todos os reativos devem ser da mais pura qualidade, tão isentos de impurezas - particularmente de ferro - quanto possivel. Todos os cuidados se devem tomar afim de se evitar que o ferro, elemento de grande ubiquidade, contamine o material com que se fazem as determinações.

\section{AGRADECIMENTO}

Deixamos aquí consignados ao Prof. Dr. Dorival Fonseca RIBEIRo, da Faculdade de Medicina Veterinária, da Universidade de São Paulo, os nossos agradecimentos pelo interesse demonstrado pelo presente trabalho durante a sua realisação, e pela amostra de hemoglobina cristalisada, por ele mesmo preparada no seu laboratório e que nos permitiu fazer com segurança uma das verificações expostas.

\section{SUMMARY}

This paper is divided into four parts.

Part $I$ revews recent advances in our knowlege of the biological function of iron.

Part II deals with colorimetric procedures for the determination of iron. Brief comments are made on seventeen methods amongst the most favoured by researchers.

Part III deals with the physiological significance of serum iron. 
Part IV is doveted to the Author's contribution to the study of serum and plasma iron. A method for the measurement of the total iron in serum or plasma, is described. It involves incubation with dilute hydrochloric acid, elimination of hemoglobin with trichloracetic acid (BARKAN) and the measurement in the ZEISS PULFRICH photometer of the iron complex of protocatechuic acid (SAlomé Pereira (65)).

Reagents

\section{METHOD}

1) Hydrochloric acid, $0.2 \mathrm{~N}$

2) Trichloracetic acid, 20 per cent solution

3) Ammonium hydroxide, $3 \mathrm{~N}$

4) Protocatechuic acid, 0.1 per cent solution in 50 per cent ethyl alcohol.

5) $N$ Ammonium hydroxide (1 part) $-N$ Ammonium sulfate (4 parts) mixture.

Procedure. Add 1 volume $(0.25$ to $1.5 \mathrm{ml})$ of reagent (1) to 2 volumes $(0.5$ to $3 \mathrm{ml})$ of blood serum or plasma in a centrifuge tube graduated at 1, 2, 3, 4, 5 and $6 \mathrm{ml}$. Keep at $37^{\circ} \mathrm{C}$ for at least 2 hours, preferably overnight. Cool to room temperature, add 1 volume $(0.25$ to $1.5 \mathrm{ml})$ of reagent (2), mix cautiously but thoroughly and let stand for 1 hour at room temperature. Centrifuge the tube for about 15 minutes at 2500 to 3000 revolutions per minute. The total volume should correspond to one of the marks on the wall of the tube; if not, make up exactly to the nearest graduation with redistilled water. The clear supernatant fluid is carefully decanted into a clean, dry test-tube $75 \times 11 \mathrm{mms}$, and as large as possible an aliquot of it is measured into a Pyrex test-tube $75 \times 11 \mathrm{mms}$. graduated at $1.5,2,2.5,3,3.5,4,4.5$ and $5 \mathrm{ml}$, with a pipette graduated to tenths. To the cold, acid solution $0.1 \mathrm{ml}$ of reagent (3) for each $\mathrm{ml}$ measured, 0.05 to $0.1 \mathrm{ml}$ of reagent (4) and reagent (5), drop by drop, are successively added with thorough mixing after each addition until the characteristi color develops. The contents of the tube are then diluted to an apropriate volume which, as a rule, should be as low as possible in order to have convenient readings in the photometer. A blank is carried through the entire procedure, at the same time, under exactly the same conditions, to serve as compensating liquid.

The photometric measurements are made with the ZEISS PULFRICH photometer. $1 \mathrm{ml}$ of the colored solution is run into the absorption 
cell of the instrument, the blank is placed in the other cell of the photometer, and the extinction is determined with the use of Filter S-50 and microcells of $50 \mathrm{mms}$ length. The extinction, $E$, is either read from a calibrated drum on the photometer or calculated from the transparency, $D$. The extinction coefficent, $k$, is then obtained by dividing $E$ by 5 , the length of the microcell used (in cms).

The color readings must be made within 8 to 15 minutes after the addition of the reagents.

Comments on the method are made.

\section{BIBLIOGRAFIA}

1) Schmidt, M. B. - 1925 - Ergebnisse der Physiologie, 24:507.

2) Anson, M. L. - Mirsky, A. E. - 1925 - Jour. Physiol., 60:161.

3) Fischer, H. - ZeILE, K. - 1929 - Liebig's Ann., 468-98.

4) Gortner, R. A. - 1938 - Outlines of Biochemistry. 2nd. ed. New York, John Wiley \& Sons, Inc.

5) Pollacci, G. - Oddo, B. - 1915 - Gazz. Chim. Ital, 45:197.

6) Oddo, B. - Pollacci, G. - 1920 - Gazz. Chim. Ital., 50:54.

7) Elvehjem, C. A. - 1935 - Physiol. Rev., 15:471.

8) Schultze, M. O. - Elvehjem, C. A. - Hart, E. B. - 1936 - Jour. Biol. Chem., 116:93.

9) Underwood, E. J. - Elvehjem, C. A. - 1938 - Jour. Biol. Chem., 124:419.

10) Соок, S. F. - 1929 - Jour. Biol. Chem., 82:595.

11) WARBURa, O. 1928 - Ober die katalytischen Wirkungen der lebenden Substanz. Berlin, Julius Springer.

12) Warburg, O. - 1928 - Chem. Ztg., 52:765.

13) Warburg, O. - 1928 - Naturwissenschaften, 16:345.

14) Stern, K. G. - 1937 - Jour. Gen. Physiol,, 20:631.

15) Sumner. J. B. - Dounce, A. L. - 1937 - Science, 85:366.

16) Keilin, D. - ManN, F. - 1938 - Apud Warburg, O. Ergebnisse der Enzymforschung, $7: 242$.

17) Apud Warburg, O. Loc. cit. (16).

18) HaAs, E. - Horecker, B. L. - Hogness, T. R. - 1940 - Jour. Biol. Chem, 136:747.

19) Theorell, H. - 1936 - Biochem. Zeitschr., 288:317.

20) Altschul, A. M. - Abrams, R. - Hognes, T. R. - 1940 - Jour. Biol. Chem., 136:777.

21) Wargurg, O. - Christian, W. - 1932, 1933 - Biochem. Zeitschr., 254:438; $257: 492$.

22) Schlesinger, H. J. - van Velkenburgh, H .B. - 1931 - Jour. Amer. Chem. Soc. 53-1212.

23) Thompson, T. G. - Bremner, R. W. - Jamieson, I. M. - 1932 - Ind. Eng. Chem. (Anal. Ed.) $4: 288$.

24) Roberts, H. L. - Beardsley, C. L. - Taylor, L. V. - 1940 - Ind Eng. Chem. (Anal. Ed.) 12-364.

25) Bernoulli, A. L. - 1926 - Helv. chim. Acta, 9:835.

26) Van URK, H. W. - 1926 - Pharmac, Weekbl, 63:1121. 
27) Lyons, E. - 1927 - Jour. Amer. Chem. Soc, 49:1916.

28) Andreasch, R. - 1879 - Ber. deuts. chem. Ges., 12:1391.

29) Cannan, R. C. - Richardson, G. M. - 1929 - Bioch. Jour., 23:1242.

30) Swank, H. W. - Mellon, M. G. - 1938 - Ind. Eng. Chem. (Anal. Ed.) $10: 7$.

31) Nagaseko, K. - 1928 - Mem. Coll. Sciences, Kyoto, Imp. Univers., $11: 109,113$.

32) Tschugaeff, L. - Orelkin, B. - 1914 - Z. anorg u. allg. Chem. 89:401.

33) FeIGL, F. - 1938 - Qualitative Analyse mit Hilfe von Tüpfelreaktionen. 3 Aufl. Leipzig, Akademische Verlagsgesellschaft M. B. H.

34) Yoe, J. H. - 1928 - Photometric Chemical Analysis I: Colorimetry. New York, John Wiley \& Sons, Inc.

35) Deniaès, G. - Chelle, L. - Labat, A. - 1930 - Précis de Chimie Analitique. 6ème. ed. Paris, Maloine.

36) Yoe, J. H. - loc. cit.

37) Snell, F. D. - 1921 - Colorimetric analysis. New York, Van Nostrand Co.

38) Denigès, G. - Chelle, L. - Labat, A. loc. cit.

39) Gregory, A. W. - 1907 - Proc. Chem. Soc., 23:263-1908-Jour. Chem. Soc. Trans., 93:93.

40) Vogel, A. - 1876 - Chem. Zentralbl., 375.

41) Pagliani, S. - 1879 - Jour. Chem. Soc., 36:748.

42) Yoe, J. H. loc. cit.

43) Snell, F. D. - SNell, C. F. - 1936 - Colorimetric methods of analysis. New York, Van Nostrand Co.

44) Mehlig, J. P. - 1938 - Ind. Eng. Chem. (Anal. Ed.) 10:136.

45) Yoe, J. H. loc, cit.

46) Конn, М. - 1922, 1923 - Monatsh. Chem., 43:373; 44:77.

47) Yoe, J. H. loc. cit.

48) Pulsifer, H. B. - 1904 - Jour. Amer. Chem. Soc., 26:967.

49) Yoe J. H. - Hall, M. G. - 1937 - Jour. Amer. Chem., Soc, 59:872.

50) Yoe, J. H. - 1932 - Jour. Amer. Chem. Soc, 54:4139.

51) Jackson, S. H. - 1938 - Ind. Eng. Chem. (Anal. Ed.) 10:302.

52) HiLl, R. - 1930 - Proc, Roy. Soc. London, B 107:205.

53) Blau, F. - 1898 - Monatschr. Chem., 19:647.

54). JaCKSON, S. H. loc. cit.

55) Lavollay, J. - $1935-$ Bull. Soc, Chim. Biol, 17:432.

56) Berg, R. - 1927 - Z. anal. Chem., 71:23.

57) Javillier, M. - Lavollay, J. - 1934 - Bull. Soc. Chim. Biol, 16:1531.

58) Saywell, L. G. - Cunningham, B. B. - 1937 - Ind. Eng. Chem. (Anal. Ed.) 9:67.

59) Blau, F. loc. cit.

60) Hummel, F. C. - Willard, H. H. - 1938 - Ind. Eng. Chem. (Anal. Ed.) $10: 13$.

61) Fortune, W. B. - Mellon, M. G. - 1940 - Ind. Eng. Chem. (Anal. Ed.) $10: 60$.

62) Howe, D. E. - Mellon, M. G. - 1940 - Ind. Eng. Chem. (Anal. Ed.) $12: 448$.

63) Ephraim, F. - 1930 - Ber. deutsch. chem Ges, 63:1928.

64) Holzer, H. - 1933 - Z. anal. Chem., 95:398. 
65) Salomé Pereira, R. - 1941 - Jour. Biol. Chem., 137:417.

66) Lutz, O. - 1907 - Chem. Ztg., 31:570.

67) Fontès, G. - Thivolle, L. - 1925 - Compts. rend. Soc. Biol., 93:687.

68) Brückmann, G. - Zondek, S, G. - 1940 - Jour. Biol. Chem, 135:23.

69) Lintzel, W. - RadefF, T. - 1928 - Bioch. Zeitschr., 203:212.

70) Barkan, G. - Schales, O. - 1937 - Zeitschr. physiol. Chem., 248-96.

71) Barkan, G. - Walker, B. S. - 1939 - Jour. Biol. Chem, 131:447.

72) Barkan, G. - Walker, B. S. - 1940 - Jour. Biol. Chem., 135-803.

73) Moore, C. - Arrowsmith, W. M. R. - Quillioan JR., J. J. - Read, J. T. - 1937 - Jour. Clin. Invest., 16:613.

74) Moore, C. - Doan, C. A. - Arrowsmith, W. M. R. - 1937 - Jour. Clin. Invest ", 16:627.

75) Thomas, J. - 1938 - Bull. Soc. Chim. Biol, 20:635.

76) Fischer, H. - Hess, R. - 1931 - Zeitschr. physiol. Chem., 194:193.

77) Barry, W. M. - Levine. V. E. - 1924 - Jour. Biol. Chem., 59:Lii.

78) Fischer, H. - Baumoartner, H. - Hess, R. - 1932 - Zeitschr. physiol. Chem., $206: 201$.

79) Warbura, O. - Negelein, E. - 1930 - Ber. deutsch. chem. Ges., 63:1816.

80) Lembero, R. - 1935 - Bioch. Jour., 29:1322.

81) Roche, J. - Bénevent, M. - 1935 - Bull. Soc. Chim. Biol., 17:1473.

82) Bing, F. C. - Hanzal, R. F. - Mrers, V. C. - 1935 - Jour, Biol. Chem., 109:viii.

83) MOORE, C. - DOAN, C. A. - ARrowsmith, W. M. R. loc. cit.

84) Fowweather, F. S. - 1934 - Bioch. Jour., 28:1160.

85) BARKAN, G. «in» Abderhalden, E. - 1935 - Handbuch der biologischen Arbeitsmethoden. 5 (8) 1207.

86) Barkan, G. - Walker, B. S. loc. cit. (71).

87) Barkan, G. - Walker, S. B. - 1940 - Jour. Biol. Chem., 135:37.

88) Lederer, J. - Maesschalck, A. - 1938 - Arch. Ind. Méd. Exp., 13:385.

89) Tompsett, S. L. - $1934-$ Bioch. Jour., 28:1536. 